\title{
GLP-1 Receptor Agonists: Beyond Their Pancreatic Effects
}

\author{
Xin Zhao ${ }^{1 \neq}$, Minghe Wang ${ }^{1 \neq}$, Zhitong Wen ${ }^{1}$, Zhihong Lu $^{1}$, Lijuan Cui ${ }^{1}$, Chao Fu ${ }^{1}$, \\ Huan Xue ${ }^{1}$, Yunfeng Liu ${ }^{2 \star \S}$ and Yi Zhang ${ }^{1 *} \S$ \\ 1 Department of Pharmacology, Shanxi Medical University, Taiyuan, China, ${ }^{2}$ Department of Endocrinology, First Hospital of \\ Shanxi Medical University, Shanxi Medical University, Taiyuan, China
}

OPEN ACCESS

Edited by:

Kazunori Sango,

Tokyo Metropolitan Institute of

Medical Science, Japan

Reviewed by:

Mohammad Qaddoumi,

Kuwait University, Kuwait

Sarah Louise Gray,

Furtwangen University, Germany

${ }^{*}$ Correspondence:

Yi Zhang

yizhang@sxmu.edu.cn

Yunfeng Liu

nectarliu@163.com

tORCID:

Yi Zhang

orcid.org/0000-0003-0305-3127

${ }^{\mp}$ These authors have contributed equally to this work and share first authorship

${ }^{\S}$ These authors have contributed equally to this work

Specialty section: This article was submitted to Clinical Diabetes,

a section of the journal

Frontiers in Endocrinology

Received: 06 June 2021 Accepted: 05 August 2021 Published: 23 August 2021

Citation:

Zhao X, Wang M, Wen Z, LuZ, Cui L, Fu C, Xue H, Liu $Y$ and Zhang $Y$ (2021) GLP-1 Receptor Agonists: Beyond Their Pancreatic Effects.

Front. Endocrinol. 12:721135. doi: 10.3389/fendo.2021.721135
Glucagon like peptide-1 (GLP-1) is an incretin secretory molecule. GLP-1 receptor agonists (GLP-1RAs) are widely used in the treatment of type 2 diabetes (T2DM) due to their attributes such as body weight loss, protection of islet $\beta$ cells, promotion of islet $\beta$ cell proliferation and minimal side effects. Studies have found that GLP-1R is widely distributed on pancreatic and other tissues and has multiple biological effects, such as reducing neuroinflammation, promoting nerve growth, improving heart function, suppressing appetite, delaying gastric emptying, regulating blood lipid metabolism and reducing fat deposition. Moreover, GLP-1RAs have neuroprotective, anti-infectious, cardiovascular protective, and metabolic regulatory effects, exhibiting good application prospects. Growing attention has been paid to the relationship between GLP-1RAs and tumorigenesis, development and prognosis in patient with T2DM. Here, we reviewed the therapeutic effects and possible mechanisms of action of GLP-1RAs in the nervous, cardiovascular, and endocrine systems and their correlation with metabolism, tumours and other diseases.

Keywords: GLP-1 receptor agonists, endocrine, cardiovascular, neurological, cancer

\section{INTRODUCTION}

Glucagon like peptide-1 (GLP-1) is a 30 or 31 amino acid long peptide hormone mainly secreted by 3 tissues in the human body: enteroendocrine L cells in the distal intestine, alpha cells in the pancreas, and the central nervous system (1). Through its interaction with the GLP-1 receptor (GLP-1R), GLP1 participates in the regulation of glucose homeostasis. In addition, glucagon like peptide-1 receptor agonists (GLP-1RAs) can be combined with GLP-1Rs, playing the same role as GLP-1. A variety of GLP-1RAs and analogues, such as exendin-4 and liraglutide, has been used successfully in the treatment of type 2 diabetes mellitus (T2DM) (2). At present, the therapeutic application and potential value of GLP-1RAs in diseases other than diabetes has become a research hotspot. Interestingly, GLP-1RAs have been reported to activate the metabolism of brown fat and increase the energy expenditure in rodents through exercise activities independent of the sympathetic nervous system pathway (3). Liraglutide has been approved by the United States Food and Drug Administration (FDA) for long-term weight management (4). Moreover, GLP-1RAs have been shown to exert many beneficial effects on vascular endothelial cells. For instance, GLP-1RAs were demonstrated to reduce the risk of cardiovascular events (5) by decreasing the blood pressure (6), improving microvascular function, and reducing inflammation (7). Further, GLP-1RAs play a 
neuroprotective effect by stimulating the differentiation of nerve cells and inhibiting neuroinflammation (8), while they were also reported to inhibit liver inflammation (9). These findings indicated that in addition to playing a role in the treatment of diabetes, GLP-1RAs can also be used in the treatment of other diseases, such as certain neurological diseases, cardiovascular diseases (CVDs), and diseases related to metabolic disorders. Many studies on the correlation between the function of GLP1RAs and the development and progression of tumors are also underway. Related studies (10) have found that GLP-1RAs can inhibit the PI3K/AKT/mTOR and ERK/MAPK pathways, thereby inhibiting the growth of prostate cancer; however, whether GLP-1RAs increase the risk of pancreatitis remains controversial (11). We here attempted to systematically review the mechanisms of action and therapeutic value of GLP-1RAs.

\section{BRIEF INTRODUCTION AND PHYSIOLOGICAL FUNCTION OF GLUCAGON LIKE PEPTIDE-1 RECEPTOR AGONISTS}

Glucagon like peptide-1 (GLP-1) is the second incretin identified in 1983. The first identified incretin was a gastric inhibitory peptide (GIP) with the activity of inhibiting the secretion of gastric acid, which was isolated from porcine small intestines (12). Briefly, GLP-1 exists in the human body in two active forms, GLP-1 (7-36 amide) and GLP-1 (7-37), with the proportion of GLP-1 (7-36 amide) being higher $(8,9)$. The half-life of natural GLP-1 is very short. Depending on the species, the half-life is approximately 1 to $2 \mathrm{~min}$ (13). There are two reasons for this: (1) after its recognition by dipeptidyl-peptidase 4 (DPP-4), GLP1 is cleaved into GLP-1(9-36) amide, which is in a low affinity; (2) kidney clearance. Glucagon like peptide- 1 receptor (GLP-1R) is a member of the $B$ family of $G$ protein-coupled receptors. In the pancreas, the interaction of GLP-1 and GLP-1R is known to mainly act through the cAMP-PKA pathway. More specifically, the interaction of GLP-1 and GLP-1R activates adenylate cyclase (AC), which stimulates the conversion of ATP to cyclic adenosine monophosphate (cAMP), thereby increasing the concentration of cAMP. In turn, cAMP further activates protein kinase A (PKA) and Rap guanine nucleotide exchange factor 4 (RAPGEF4, also known as EPAC2) (14). The activated
PKA can close the ATP-dependent $\mathrm{K}^{+}$channel and depolarize the cell membrane, while also activate the voltage-dependent $\mathrm{Ca}^{2+}$ channel, causing a $\mathrm{Ca}^{2+}$ inflow and the generation of action potentials (15). In addition, PKA can also promote $\mathrm{Ca}^{2+}$ release by activating inositol triphosphate (IP3). The activated EPAC2 can further activate Ras protein 1 and phospholipase $C$, which activate the IP3 and diacylglycerol (DAG) pathways and promote the release of $\mathrm{Ca}^{2+}(16)$. All these pathways eventually lead to an increase in the intracellular $\mathrm{Ca}^{2+}$ concentration, thereby promoting the mitochondrial synthesis of ATP, and the release of insulin particles into the blood through exocytosis. Apart from the pancreas, GLP-1R is also widely distributed in various tissues of the body including the lungs, kidneys, central nervous system, cardiovascular system, gastrointestinal tract, and skin and vagus nerves (17). This distribution breadth of GLP-1R further highlights the diversity and importance of its biological functions.

Glucagon like peptide-1 receptor agonists (GLP-1RAs) are emerging glucose control drugs, which are widely used in the treatment of T2MD in recent years. Due to the wide distribution of GLP-1R, GLP-1RAs also have a wide range of pharmacological effects. At present, existing GLP-1RAs mainly include 2 types: polypeptide and non-polypeptide (18). Based on similarities in their amino acid sequence, peptide agonists are mainly divided into GLP-1 and derivatives and exendin-4 and derivatives. Common GLP-1RAs are listed in Table 1. In addition to lowering the levels of blood glucose, as shown in Figure 1, GLP-1RAs have also been shown to have a positive effect on multiple human tissues. Liraglutide, which has been approved for reducing the risk of T2MD, has also been found to reduce the risk of major cardiovascular events in adults with established CVDs (19). Accordingly, the guidelines of the American Diabetes Association recommend it as a second-line drug after metformin, suitable for patients with known atherosclerotic cardiovascular disease (20). Moreover, liraglutide was reported to reduce the abnormal proliferation of hyperglycaemia-induced vascular smooth muscle cells by inhibiting the PI3K/AKT and ERK 1/2 signaling pathways (21). Due to the metabolic regulatory function of GLP-1RAs, they have also been considered for the treatment of other diseases such as obesity, liver disease and other metabolic dysfunction diseases (22).

In non-alcoholic fatty liver disease (NAFLD) mice (23), liraglutide was shown to inhibit the MKK4/JNK signaling

TABLE 1 | Classification of GLP-1RAs.

\begin{tabular}{|c|c|c|c|}
\hline Name & Listing situation & Molecular formula & Molecular weight \\
\hline Exenatide & Yes & $\mathrm{C}_{149} \mathrm{H}_{234} \mathrm{~N}_{40} \mathrm{O}_{47} \mathrm{~S}$ & 3369.76000 \\
\hline Liraglutide & Yes & $\mathrm{C}_{172} \mathrm{H}_{265} \mathrm{~N}_{43} \mathrm{O}_{5} 1$ & 3751. 20Da \\
\hline Lixisenatide & Yes & $\mathrm{C}_{215} \mathrm{H}_{347} \mathrm{~N}_{61} \mathrm{O}_{65} \mathrm{~S}$ & 4858.50000 \\
\hline Albiglutide & Yes & $\mathrm{C}_{148} \mathrm{H}_{224} \mathrm{~N}_{40} \mathrm{O}_{45}$ & 3283.65000 \\
\hline Dulaglutide & Yes & $\mathrm{C}_{2646} \mathrm{H}_{4044} \mathrm{~N}_{704} \mathrm{O}_{836} \mathrm{~S}_{18}$ & 59669.00000 \\
\hline Semaglutide & Yes & $\mathrm{C}_{187} \mathrm{H}_{291} \mathrm{~N}_{45} \mathrm{O}_{59}$ & 4113.57754 \\
\hline Beinaglutide & Yes & $\mathrm{C}_{149} \mathrm{H}_{225} \mathrm{~N}_{39} \mathrm{O}_{46}$ & 3298.7Da \\
\hline Supaglutide & Clinical Trials & Waiting to be published & Waiting to be published \\
\hline PEG-loxenatide & Yes & $\mathrm{C}_{210} \mathrm{H}_{325} \mathrm{~N}_{55} \mathrm{O}_{69} \mathrm{~S} \cdot\left(\mathrm{C}_{2} \mathrm{H}_{4} \mathrm{O}\right)_{2 \mathrm{n}}$ & $44212.65 \pm 4000 \mathrm{Da}$ \\
\hline
\end{tabular}




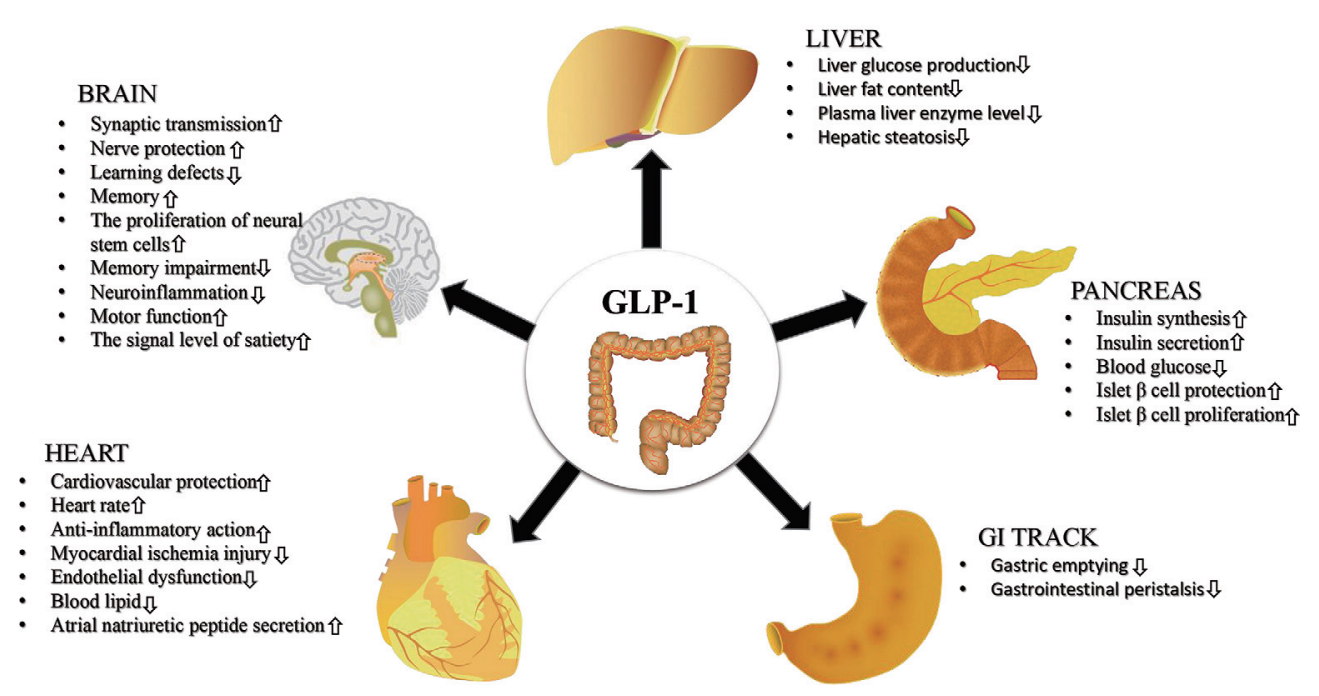

FIGURE 1 | The effects of GLP-1RAs on multiple human organizations. GLP-1RAs exert a positive therapeutic effect on human brain, pancreas, heart, gastrointestinal tract (Gl tract) and liver.

pathway, thereby improving the hypoadiponectinemia-induced inflammatory stress. In addition, GLP-1RAs (24) have also been found to play an active role in the treatment of polycystic ovary syndrome (PCOS). Besides, the protective and therapeutic effects of GLP-1RAs on the central nervous system have now been confirmed by several studies $(25,26)$. In particular, they have been reported to stimulate nerve differentiation, enhance synaptic plasticity, promote nerve cell survival, and prevent and treat Alzheimer's disease (AD), Parkinson's disease (PD), stroke and other neurological diseases by regulating the expression of some key enzymes and the release of certain neurotransmitters (27). In addition, a number of studies have also shown that GLP-1RAs has a positive effect on the treatment of certain tumors (10).

\section{EFFECTS OF GLUCAGON LIKE PEPTIDE-1 RECEPTOR AGONISTS ON THE NEUROLOGICAL SYSTEM}

Autoradiography of human tissue sections with ${ }^{125}$ I-labelled GLP-1 (7-36 amide) revealed a high content of GLP-1R in the central nervous system suggesting its potentially important role in the nervous system (28). More specifically, GLP-1R is widely expressed in the periphery of the central nervous system, including the hippocampus, neocortex, hypothalamus, spinal cord and cerebellum (29). In recent years, a variety of mechanisms for the beneficial effects of GLP-1RAs on the brain have been discovered, including the reduction of neuroinflammation and increase of signal transduction in surviving cells. In addition, they have been shown to enhance synaptic transmission and counteract learning deficits $(30,31)$. A recent study found that exendin- 4 could improve the reference memory ability of adult rats (32). The use of GLP-1RAs could promote the proliferation of adult rodent neural stem cells, indicating their role in promoting brain regeneration $(33,34)$. The therapeutic effect of GLP-1RAs on neurological diseases has been confirmed by several studies.

\section{EFFECTS ON ALZHEIMER'S DISEASE}

Alzheimer's disease (AD) is a progressive and irreversible neurodegenerative disease, with unclear aetiology and pathogenesis. Approximately $6-8 \%$ of people over the age of 65 suffer from $\mathrm{AD}$; this risk is known to increase with age, and is more common in women (1.5 times compared with men) (35). A study has suggested that the accumulation of amyloid- $\beta$ (A $\beta)$ deposits triggers a series of pathological processes, such as inflammation, tau angle formation, synaptic dysfunction, and cell death, which lead to neurodegenerative behavior and eventually to the development of dementia (36). According to some researchers, the abnormal accumulation of $A \beta$ and tau protein is the cause of $\operatorname{AD}(37,38)$. However, some studies have indicated that these are manifestations and not the cause of the disease $(39,40)$. The main pathological features of AD include the deposition of insoluble $A \beta$ that forms senile plaques, neurofibrillary tangles, and neuronal apoptosis (40). Neurofibrillary tangles have been found in the amygdala, hippocampal structure, parahippocampal gyrus, and temporal cortex of patients with $\mathrm{AD}$, whereas senile plaques have been shown to be distributed throughout the combined neocortex and striatum (41). Interestingly, $\mathrm{AD}$ has been associated with a dysfunction in insulin signaling in the brain. A Rotterdam study has shown that the risk of $\mathrm{AD}$ in patients with T2MD is increased by 2 -fold (42). Moreover, insulin resistance(IR) has also been reported in the brain of patients with AD. Due to IR, the brain cannot use glucose, thus leading to inflammation and the deposition of plaques and tangles (43). 
In an $\mathrm{AD}$ mouse model, GLP-1RAs were demonstrated to reduce the levels of $\mathrm{AD}$ pathological markers, including oligomeric antibodies and antibody plaque load, reduce the activation of microglia, and improve memory behavior $(35,44,45)$. Furthermore, GLP-1RAs were found to protect hippocampal neurons from cell necrosis caused by glutamate, $\mathrm{Fe}^{2+}$ and hypoxia. Calcium is also known to play an important role in neuronal plasticity and neurodegenerative diseases. In a study using cultured rat hippocampal neurons, pre-treatment of nerve cells with GLP-1 resulted in a weakened $\mathrm{Ca}^{2+}$ response to glutamate and weakened membrane depolarization (46). Wholecell patch clamp analysis showed that glutamate-induced currents and voltage-dependent calcium channel currents were significantly reduced in GLP-1-pre-treated neurons. Pretreatment of neurons with GLP-1 significantly reduced the susceptibility of glutamate-induced neuronal death. A basic study suggested that semaglutide protects neurons from $A \beta$ toxicity potentially through the enhancement of autophagy and the inhibition of apoptosis (47). Zhou et al. found that the protective effect of dulaglutide on learning and memory impairment might be the result of reducing the hyperphosphorylation of tau and neurofilament proteins in a PI3K/AKT/GSK3 $\beta$ signaling pathway-dependent manner (48). Two types of GLP-1RAs, liraglutide and exenatide, were found to be antagonistic to the neurodegeneration and $\mathrm{AD}$ progression even in mice without diabetes $(35,49)$. McClean et al. (35) showed that systemic administration of liraglutide in $\mathrm{AD}$ transgenic mice for 8 weeks could prevent memory impairment, neuronal loss, and deterioration of hippocampal synaptic plasticity. In addition, according to the numbers of activated microglia, liraglutide could significantly reduce both the deposition of amyloid plaques and inflammation (50). Similarly, in rats injected with monoclonal antibodies (mAbs) in the hippocampus, pre-treatment with liraglutide significantly protected from the mAbs-induced damage of spatial memory and long-term potentiation (51). Importantly, liraglutide was not only shown to have a preventive effect, but also reversed some of the key pathological features of late AD in mice (52). Another GLP-1 analogue, exenatide, has also shown promising results against neurodegenerative diseases in a pre-clinical study (53). Conclusively, GLP-1RAs have great research potential in the field of $\mathrm{AD}$ treatment.

\section{EFFECTS ON PARKINSON'S DISEASE}

Parkinson's disease (PD) is a chronic neurodegenerative disease that affects the central nervous system and the second most common neurodegenerative disease after AD (54). It mainly affects the motor nervous system, and is associated with the loss of Lewy bodies and substantia nigra dopamine neurons (55). The Lewy body is a neuron inclusion body, mainly composed of $\alpha$ synuclein (56). Dopamine, which acts as a neurotransmitter, is known to play a key role in movement control. However, the reason behind the loss of these dopamine-producing nerve cells remains unclear (57). The most obvious symptoms of PD in the early stages are tremor, limb stiffness, decreased motor function and abnormal gait. Cognitive and behavioral problems might also manifest. In the late stages of $\mathrm{PD}$, the key molecular pathogenic mechanisms include the misfolding and aggregation of $\alpha$ synuclein, mitochondrial dysfunction, impaired protein clearance (related to inefficient ubiquitin-proteasome and autophagy-lysosomal systems), neuroinflammation and oxidative stress (57). To date, no therapeutic approach has been shown to either completely cure PD or delay, stop, and reverse the degeneration and death of dopaminergic neurons (58). Therefore, effective neuroprotective therapies are continuously being pursued. Increasing evidence has demonstrated that GLP-1 analogues can cross the blood-brain barrier, protect dopaminergic neurons in the substantia nigra, and rescue motor activity and cognitive functions in PD animal models (59-61). These findings have strongly supported the hypothesis that the use of GLP-1RAs might be a novel effective treatment for PD.

Disturbance of insulin signaling in diabetic patients might lead to the abnormal expression of $\alpha$ Syn, damage to mitochondrial function, increase in mitochondrial oxidative stress, and down-regulation of the PI3K/AKT pathway, which in turn could promote the occurrence and development of PD (62). Surprisingly, GLP-1RAs, such as liraglutide, lixisenatide, and semaglutide, have showed outstandingly neuroprotective effects on animal models of PD $(63,64)$. Bertilsson et al. found that intraperitoneal injection of exendin- 4 increased the number of BrdU-positive progenitor cells in the subventricular zone (33), indicating that exendin-4 could compensate for the loss of dopaminergic neurons in the PD model by promoting the formation of substantia nigra neurons. Similarly, in a 1methyl-4-phenyl-1,2,3,6-tetrahydropyridine (MPTP)-induced PD mouse model, GLP-1 analogues were reported to protect the brain from MPTP-induced pathological effects, such as movement disorders, increased levels of $\alpha$-synuclein, chronic inflammation in the brain, loss of dopaminergic neurons, oxidative stress, and expression of growth factors (65). The novel GLP-1RA geniposide was found to up-regulate the expression of $\beta$-cell lymphoma 2 (Bcl-2), whereas reduce the activity of caspase 3 , thereby protecting dopaminergic neurons in a MPTP mouse model of PD (66). Inflammation is increasingly recognized as a key factor in the pathogenesis of PD (67). Therefore, the regulation of the activity of microglia is believed to play a key role in the neuroinflammation of PD. Positron emission tomography of patients with early PD showed a significant increase in the activation of microglia (68), which might lead to neuron loss in PD and AD (69).

Injection of exendin- 4 into rodents after endotoxin and $\mathrm{mTP}$ toxin-induced damage to the substantia nigra striatum could prevent the toxin-induced activation of microglia and inhibit the production of pro-inflammatory cytokines (70). Mitochondrial function interference or mitochondrial damage is also one of the mechanisms of pathogenesis of PD (71). Interestingly, GLP1RAs have also been shown to exert multiple effects on mitochondria. For example, saxagliptin protected the mitochondrial function in $\mathrm{PD}$ rat models by up-regulating 
complex I and the anti-apoptotic protein Bcl-2 (72), while longterm use of exendin-4 in rodents promoted the function of hippocampal nerves, and improved motor function and behavior (73). Moreover, GLP-1RAs were shown to protect neurons and induce beneficial changes in neuroplasticity in laboratory models of several neurological diseases, including PD (31). In a pre-clinical trial, patients with moderate PD who received subcutaneous injection of $2 \mathrm{mg}$ exenatide once a week had an advantage of 3.5 points in the mds-updrs exercise scale over the placebo group (74). Zhang et al. found that semaglutide could reverse the decrease in the levels of tyrosine hydroxylase, alleviate inflammation, and increase autophagy, thus protecting dopaminergic neurons in substantia nigra and striatum (75). Another study showed that the incidence of PD diagnosed with T2DM varies greatly depending on the administered diabetes treatment. Compared with other oral hypoglycemic agents, the prevalence of PD when using DPP4 inhibitors and GLP-1RAs was shown to be $36-60 \%$ lower (76). These results indicated that GLP-1RAs might play a useful role in the future treatment of PD.

\section{EFFECTS ON STROKE}

Stroke is the second leading cause of death and the leading cause of disability worldwide. Strokes are mainly divided into hemorrhagic and ischemic strokes caused by blood vessel obstruction. Strokes are mostly caused by arterial occlusion, which in turn leads to cerebral ischemia, brain damage, and then nerve damage and disability. Typical symptoms of stroke include sudden unilateral weakness, numbness or loss of vision, diplopia, changes in speech, ataxia, and non-orthogonal vertigo (77). Atypical symptoms include isolated vertigo, blindness in both eyes, amnesia, agnosia, dysarthria, dysphagia, stridor, headache, hemiplegia, confusion, and changes in consciousness (77). The pathological mechanism of stroke mainly includes the apoptosis of neurons in the cerebral cortex and striatum. As neurological and medical complications after stroke are not properly predicted, prevented, or dealt with, they are considered to constitute the main cause of the high morbidity and mortality associated with strokes (78). In addition, T2DM is associated with an increased risk of stroke and mortality after stroke (79). Interestingly, GLP-1RA antidiabetic drugs have shown a distinct effect in reducing the incidence of stroke and enhancing neuroprotection in both pre-clinical and clinical studies $(80,81)$.

A pre-clinical study showed that exendin-4 had a remarkable neuroprotective effect, improving the neurological deficit caused by transient middle cerebral artery occlusion in mice, and reducing neuronal loss and microglial inflammation (82). Acute administration of exendin-4 at the beginning of the stroke or $1 \mathrm{~h}$ later was reported to have a significant effect; however, this neuroprotective effect disappeared after $3 \mathrm{~h}$. The neuroprotective effect of exendin- 4 was found to be independent of the glucose-increasing effect, whereas related to increasing the levels of cAMP and reducing oxidative stress and the inflammatory response (83). Relevant studies have found that exendin-4 could mediate the neuroprotective effect on $\gamma$ aminobutyric acid neurons in the piriform cortex and striatum and play a neuroprotective role in a cAMP/PKA- and PI3K/ AKT-dependent manner after stroke $(84,85)$. Sato et al. found that intraperitoneal injection of liraglutide $2.5 \mathrm{~h}$ after stroke induced neuroprotection in rats, which was related to the upregulation of vascular endothelial growth factor (VEGF) (86). A study on the protective mechanism of liraglutide on cortical neurons after ischemia suggested that liraglutide probably reversed the ischemia-induced apoptosis by activating the PI3K/AKT and MAPK pathways (87). Another study on the effect of dulaglutide on stroke showed that dulaglutide reduced the incidence of stroke in middle-aged and elderly people with T2MD and other cardiovascular risk factors, but it cannot reduce the severity of stroke (88). A trial of reperfusion therapy for ischemic stroke indicated that semaglutide, which has a strong GLP-1R-mediated neuroprotective effect, could reduce the infarct size in acute ischemic stroke in non-diabetic rats (89). In addition, the activation of GLP-1R was shown to promote synaptic plasticity and axonal growth (30), and stimulate adult neurogenesis (90). These findings might lay the foundation for the potential regenerative treatment of patients with chronic stroke.

\section{EFFECTS ON CHRONIC PAIN}

Pain is an unpleasant subjective and emotional experience related to actual or potential tissue damage (91). Pain can be divided into acute and chronic pain (92). Compared with acute pain, chronic pain is known to be much more harmful to the human body (93). Continuous pain can induce more serious pathological reactions in the human body, and even cause shock or death. Therefore, the treatment of chronic pain is even more important. Clinically, treatment drugs for chronic pain are mainly non-steroidal anti-inflammatory analgesics, opioid analgesics, and auxiliary drugs: such as antidepressants and anxiety drugs (94). However, the adverse reactions caused by these drugs often limit their application. In particular, long-term use of non-steroidal anti-inflammatory drugs (NSAIDs) can cause gastric mucosal damage as they can inhibit mitochondrially encoded cytochrome C oxidase I (MT-CO1, also known as COX-1) and block its protective effect on gastric mucosa. Therefore, the use of NSAIDs is usually associated with damage to the gastrointestinal tract and other systems during treatment, and thus need to be used with caution (95). In recent years, there have been numerous crises caused by the abuse of opioids. The nervous system can quickly develop tolerance to the drug. Overuse of opioids might lead to serious consequences, such as respiratory depression, addiction, and even death (96, 97). Studies found that intrathecal injection of GLP-1RAs effectively reduced formalin-induced peripheral nerve injury, as well as cancer- and diabetes-induced pain without causing serious adverse reactions. Moreover, it was also reported that long-term injection of geniposide and exenatide did not induce nociceptive tolerance $(98,99)$. Hence, GLP-1RAs $(98)$ appear to 
be potential alternatives for the treatment of chronic pain due to their effect in reducing pain while not affecting acute injury. Previous experiments have found that exendin-4 could reduce the pain-induced neuro-inflammatory response through the GLP-1R pathway, thereby promoting the recovery of cognitive function in mice (100). Likewise, the anti-dipeptidyl peptidaseIV GLP-1RA ROSE-010 was shown to effectively relieve the intestinal pain induced by irritable bowel syndrome (101). However, there have been relatively few studies on the mechanism of GLP-1RAs in the treatment of chronic pain.

Surprisingly, a recent study found that liraglutide blocked the lipopolysaccharide-induced visceral allodynia in a NO-dependent manner. It was suggested that this was achieved by inhibiting the production of pro-inflammatory cytokines and reducing the increase in intestinal permeability (102). As shown in Figure 2, following stimulation of GLP-1R by exenatide on microglia, the cAMP/PKA/p38ß/CREB signal transduction pathway is activated, promoting the expression of IL-10. Subsequently, the IL-10 receptor/STAT3 signaling pathway in microglia is autocrinally activated, thereby promoting the expression and release of $\beta$ endorphin, the latter acts on $\mu$-opioid receptors on neurons to produce analgesic and neuroprotective effects (103-105).

The various aforementioned GLP-1RAs are peptides that are easily hydrolyzed by proteases, thus making their oral use basically ineffective. Therefore, discovering a small molecule GLP-1RA that could be orally administered is a current but extremely challenging research hotspot. Interestingly, W-24
(106), a non-peptide GLP-1RA, has been reported to inhibit inflammatory pain by stimulating the spinal cord GLP-1R for the release of analgesic $\beta$-endorphin. Moreover, as a small molecule drug, it could increase the confidence of in-depth research to find oral GLP-1RAs in the treatment of chronic pain.

\section{EFFECTS OF GLUCAGON LIKE PEPTIDE-1 RECEPTOR AGONISTS ON THE CARDIOVASCULAR SYSTEM}

Cardiovascular diseases (CVDs) are the main cause of premature death among Chinese individuals (107). In the cardiovascular system, GLP-1R is known to exist not only on cardiomyocytes and endothelial cells, but also in the autonomic nervous system, Figure 3 suggests that GLP-1R may have direct and indirect effects on the heart and blood vessels. Moreover, it has been reported that GLP-1RAs increase the heart rate to a certain extent. However, this effect is soon weakened, not affecting the normal heart rate (108). The cardioprotective effects of GLP1 RAs include anti-inflammatory actions, reduction of myocardial ischemia injury, modifications in the synthesis and secretion of lipids, and improvement of endothelial dysfunction (109). A cardiovascular prognosis evaluation trial of semaglutide in the treatment of T2DM reported that administration of semaglutide reduced the cardiovascular prognostic risk (110).

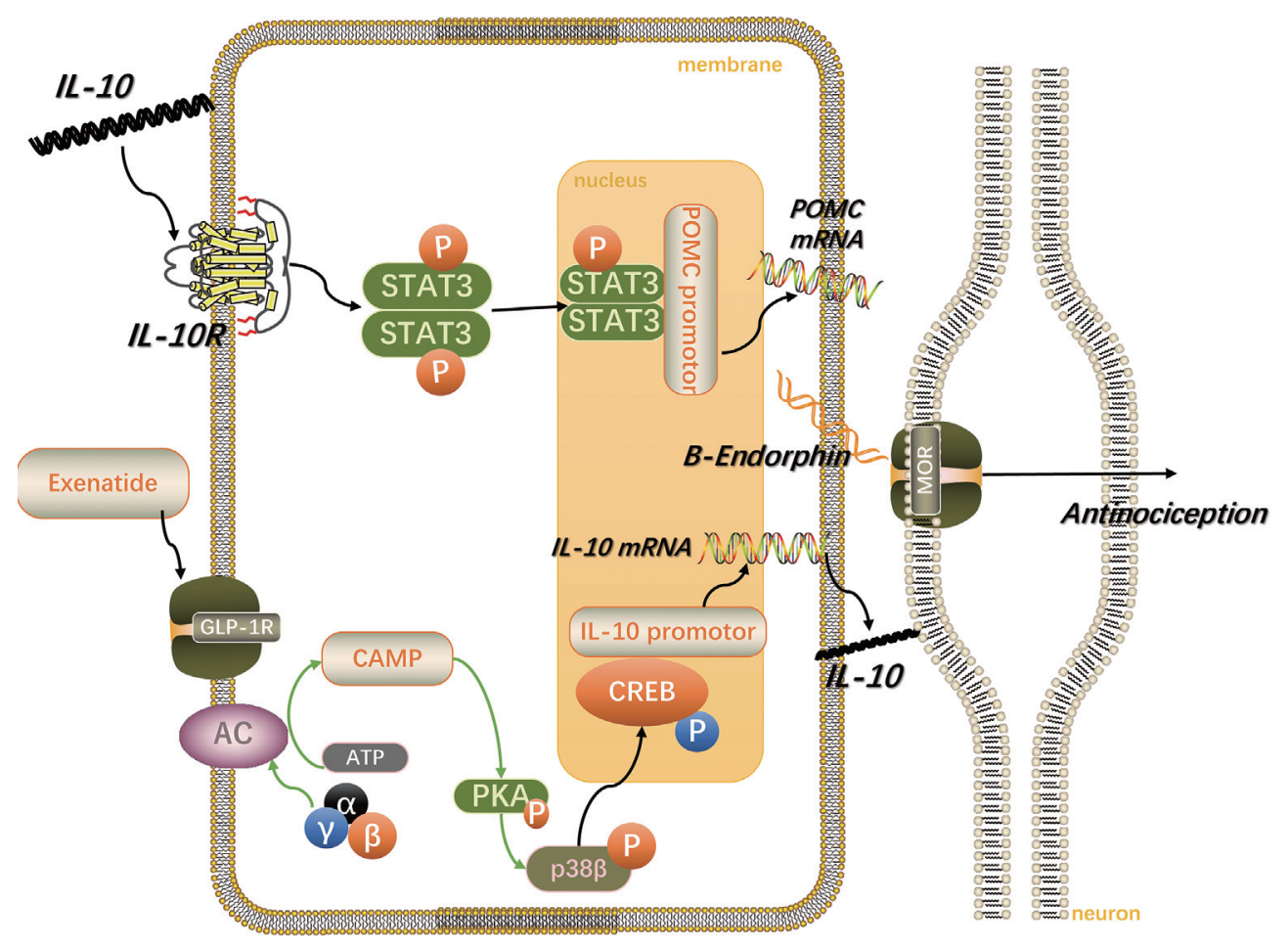

FIGURE 2 | Spinal microglia GLP-1R/IL-10/ $\beta$-endorphin analgesic pathway. IL-10 stimulates the GLP-1R activation-induced microglial expression of $\beta$-endorphin and neuropathic spinal cord anti-allergic response in an autocrine manner. The figure is modified from Ref 103. 


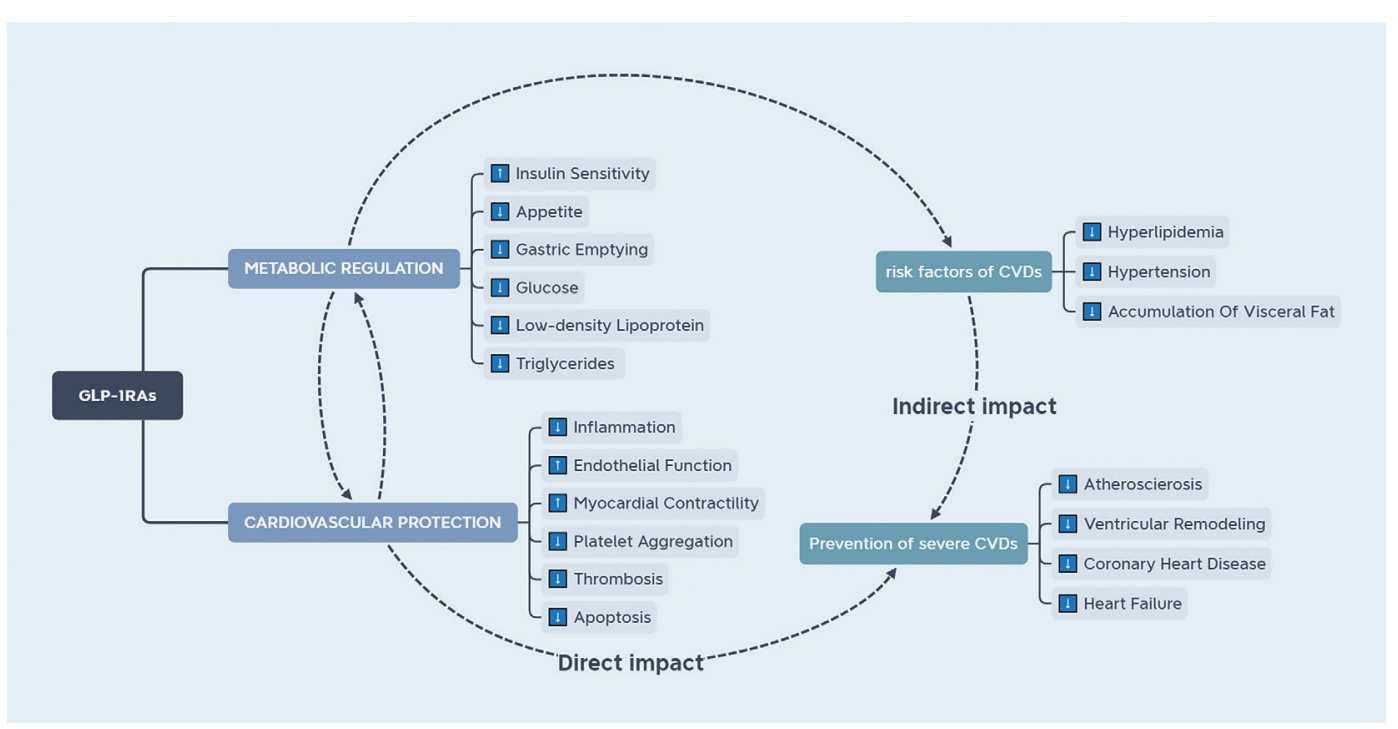

FIGURE 3 | The effect of GLP-1RAs on the cardiovascular system. GLP-1RAs have direct and indirect effects on the cardiovascular system. Endocrine factors can ameliorate the risk factors for cardiovascular diseases.

Nonetheless, the mechanism underlying the effects of GLP-1RAs in the cardiovascular system remain unclear. Many studies have shown that GLP-1RAs can treat certain CVDs, such as atherosclerosis and hypertension, and the suggested mechanism involves more than blood glucose control $(111,112)$. Therefore, the benefits of GLP-1 and GLP-1-based therapies for the cardiovascular system have attracted increased attention from clinicians.

\section{EFFECTS ON ATHEROSCLEROSIS}

Atherosclerosis (AS) is a fibrolipopathic formation on the arterial wall and a main cause of death worldwide. In particular, superimposed thrombosis is responsible for the most devastating consequences of AS, such as heart attacks and strokes. Elevated levels of plasma cholesterol constitute the most important factor in the development of AS (113). Briefly, the development of atherosclerotic lesions requires the action of low-density lipoprotein (LDL), which carries cholesterol through the blood (114). Over time, AS plaques form fibrous caps and accumulate calcium salts. Advanced AS plaques can often invade the arterial lumen, obstruct blood flow and cause tissue ischemia. In addition, following the collapse of an aneurysm, its contents are released in the blood flow, inducing thrombosis; the formed thrombus then blocks the lumen, also inducing tissue ischemia; usually with a more rapid onset (115). Inflammation is also known to be a key factor in the development of AS: the aggregation of white blood cells, mainly macrophages, is a significant feature of AS from its initial to its late stage (116).

A number of studies has found that semaglutide and liraglutide could reduce the levels of blood lipids and blood pressure (BP), hence contributing to the reduction of atherosclerosis and CVDs (117-119). Moreover, GLP-1RAs were reported to inhibit the development of AS in animal models. The anti-AS effects of GLP-1RAs include the regulation of inflammation (109), reduction of intima-media thickening (120), improvement of blood lipid profile (121), and regulation of endothelial dysfunction (122); however, the specific mechanism remains unclear.

As mentioned, GLP-1RAs can reduce the content of systemic inflammation markers. Importantly, controlling inflammation is believed to contribute in the prevention of cardiovascular diseases (123). In one study, liraglutide and semaglutide were reported to mitigate the development of plaque lesions by changing the inflammatory pathway in a mouse model of AS (124). Besides, GLP-1RAs might be driven by anti-inflammatory mechanisms to inhibit the formation of macrophage foam cells and thus slow down the pathological processes of AS $(125,126)$. Liraglutide was found to directly affect the formation of atherosclerotic lesions by tilting the macrophage population to the M- $\Phi-2$ phenotype that is conducive to decomposition (127). Although this was demonstrated in animal experiments, GLP-1 was shown to exert acute anti-inflammatory and antioxidant effects on humans under specific conditions. Interestingly, these effects were found to not be simply regulated through the control of the levels of insulin (123). A number of studies has found that liraglutide prevented these AS effects of ox-LDL by preventing the inhibitory effect of the p53 protein on kruppel-like factor 2 (KLF2) of human aortic endothelial cells $(114,128)$. Of note, KLF2 has been shown to play an important role in protecting vascular endothelial cells from ox-LDL and oscillatory shear damage. As such, this finding provides a new option for preventing the development of AS. Another GLP-1 analogue, lixisenatide, was reported to prevent the acuteness of cardiovascular events in apolipoprotein $\mathrm{E}^{-/}$insulin receptor 
substrate $2^{+/-}\left(\mathrm{APOE}^{-/-} \mathrm{irs}^{+/-}\right)$mice by reducing the size of AS plaques, increasing plaque stability, and promoting the conversion of macrophages to the anti-inflammatory M2 phenotype (129). In addition, liraglutide could also induce the cell cycle arrest of vascular smooth muscle cells through the AMPK pathway, thereby delaying the formation of AS (130). Although there is no GLP-1RA approved for the treatment of AS, these findings could provide novel approaches for the treatment of AS.

\section{EFFECTS ON HYPERTENSION}

Hypertension poses an increasingly serious public health problem worldwide. Hypertension can be divided into primary and secondary hypertension. Secondary hypertension is usually associated with an earlier age of onset, no family history, and a clear cause, such as renal or endocrine disorders, or iatrogenic triggers, such as the use of oral contraceptives (131). However, 90-95\% of cases of hypertension are essential hypertension. Essential hypertension mostly occurs in middle-aged and elderly people, and is the result of the combination of lifestyle and genetic factors (132). Hypertension is the most common preventable risk factor for CVDs (including coronary heart disease, heart failure, stroke, myocardial infarction, atrial fibrillation, and peripheral artery disease), chronic kidney disease, and cognitive impairment, and also the main single factor for deaths and disability worldwide (133). The pathophysiological mechanism of hypertension is very complicated. The human body has a complex mechanism for maintaining the levels of blood pressure, including the reninangiotensin-aldosterone system, natriuretic peptides, endothelial-sympathetic nervous system, and the immune system (134). Genetic factors are also implicated in the development of hypertension. For instance, the pathogenesis of essential hypertension involves multiple genes; certain allelic variants of several genes have been associated with an increased risk of essential hypertension, and almost all cases are known to be related to a familial history of hypertension (135). Finally, vasoactive substances produced by vascular endothelial cells are also important factors in the regulation of blood pressure.

A meta-analysis conducted by Wang et al. (136) showed that GLP-1RAa have the effect of lowering blood pressure. In particular, they found that the activation of GLP-1R promoted the secretion of atrial natriuretic peptide (ANP) and lowered blood pressure. In animal experiments, the GLP-1RA liraglutide was found to stimulate the secretion of ANP by increasing the levels of Epac2, which is a downstream target of GLP-1R signaling in cardiomyocytes (132), However, this finding seemed to contradict the results of clinical studies in which no increase was observed in the levels of ANP in healthy people and patients with T2MD. A study of patients with T2MD and congestive heart failure found that their levels of ANP were increased, whereas blood pressure was decreased, indicating that the GLP-1R-ANP axis is only active in patients with congestive heart failure (123). Despite the controversies about the expression of GLP-1R in vascular smooth muscle and endothelial cells, studies have shown that GLP-1RAs have anti-proliferative effects on these cells, and also reduced oxidative stress and increased the production of nitric oxide (NO) $(137,138)$. These effects have been confirmed in animal experiments, but not in humans, and the specific mechanism remains unknown. Nonetheless, these findings have already suggested the protective effect of GLP-1RAs on hypertension and atherosclerosis.

\section{EFFECTS OF GLUCAGON LIKE PEPTIDE-1 RECEPTOR AGONISTS ON ENDOCRINE METABOLISM}

Interestingly, GLP-1RAs not only exert a protective effect on the nervous and cardiovascular systems, but also exhibit a regulatory effect on metabolism. Figure 4 illustrates the potential pathways of the function of GLP-1RAs against multiple diseases. For instance, GLP-1RAs can improve the levels of insulin, regulate the levels of sex hormone, improve the blood lipid profile, increase the levels of adiponectin, regulate autophagy, inhibit the production of liver glucose, reduce the liver fat content, as well as reduce the levels of plasma liver enzymes and liver steatosis. They can also be used to prevent and treat endocrine disorders or metabolic diseases such as polycystic ovary syndrome (PCOS), obesity, and non-alcoholic fatty liver disease (NAFLD) (135).

\section{EFFECTS ON POLYCYSTIC OVARY SYNDROME}

Polycystic ovary syndrome (PCOS), which is mainly manifested as sparse ovulation or non-ovulation, high levels of androgens, ovarian polycystic changes, obesity, and infertility, is the most common endocrine and metabolic disorder in women of childbearing age (139). When accompanied by metabolic disorders, such as IR and dyslipidaemia, it can lead to hyperlipidaemia, hypertension, metabolic syndrome and diabetes. In addition, skin problems such as hirsutism and androgenic alopecia cowing to the excessive levels of androgens might also occur (140-143). Although the pathogenesis of PCOS has not been fully elucidated, recent studies have indicated that excess levels of androgens might be the main pathogenic causative factor of PCOS (144-146). Patients with PCOS are frequently characterized by other symptoms, such as obesity and IR (147).

In women with PCOS, high concentrations of leptin have been reported to inhibit the expression of aromatase mRNA in granulosa cells, while the hyperandrogenic follicular environment in GCs was found to significantly reduce the expression of P450arom, which can convert androgens into estrogen, further increasing the levels of androgens and ultimately promoting follicular atresia (148-150). The high levels of free fatty acids (FFAs) are the main manifestation of 


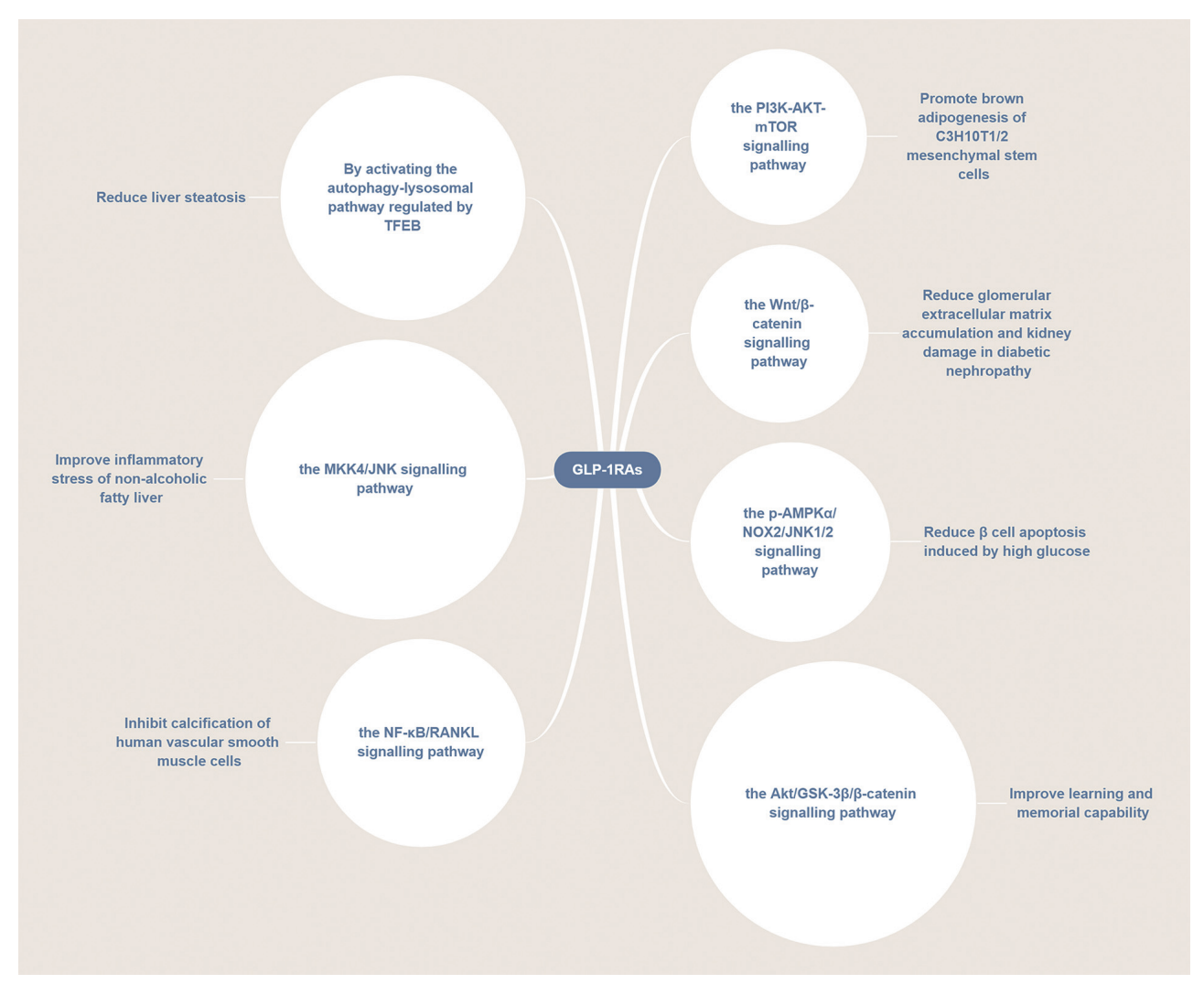

FIGURE 4 | GLP-1RAs are involved in a variety of disease pathways. GLP-1RAs can activate several signaling pathways, such as the PI3K/AKT/mTOR, p-AMPK $\alpha /$

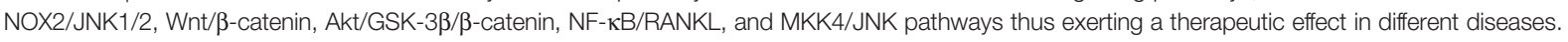

obesity. Briefly, FFAs can reduce the tyrosine phosphorylation of insulin receptor substrate-1 by activating the serine/threonine kinase, thereby aggravating IR (151). Moreover IR in PCOS was shown to destroy the effect of gonadotropins, enhance the sensitivity of follicular membrane cells to the luteinizing hormone, and increase the expression of $\mathrm{P} 450 \mathrm{c} 17$ and $3 \beta$ hydroxysteroid dehydrogenase type 2, leading to increased production of androgen (152). Concomitantly, the increased levels of insulin reduce the binding of liver sex hormone binding globulin SHBG to testosterone, leading to hyperandrogenism (153). Increased evidence have suggested that higher levels of androgen might cause follicular dysplasia, which is the main cause of insufficiency of ovulation (154).

Related studies have indicated a causal relationship between IR and all clinical symptoms of PCOS, with weight loss being shown to improve the reproductive function, hyperandrogenism and metabolism of women with PCOS $(155,156)$. Accordingly, GLP1RAs have been increasingly used in the treatment of PCOS because of their ability to reduce weight and improve IR (155-159). Surprisingly, most studies have shown that GLP-1RAs not only can reduce the weight of patients with PCOS, but also have a positive effect on the levels of androgens $(160,161)$. However, there have been few studies on the potential mechanism of the action of GLP-1RAs in the treatment of PCOS. Some studies have suggested that the proliferation and apoptosis of granulosa cells (GCs) are the root causes of follicular development and atresia, with forkhead box protein O1 (FoxO1) playing an important role in promoting PCOS follicular atresia and GCs apoptosis $(162,163)$. The GLP-1/GLP-1R axis was demonstrated to enhance the activity of PCOS ovarian granulosa cells by partially modifying the FoxO1 phosphorylation sites, thereby promoting oocyte maturation (164). In addition, liraglutide was found to repair the cognitive impairment in a rat model of PCOS by inhibiting the overexpression of the Notch signaling pathway (165). Therefore, GLP-1RAs appear to have a beneficial role in the treatment of POCS; however, the specific mechanism of action needs to be studied in depth (166).

\section{EFFECTS ON OBESITY}

Obesity, as a chronic recurrent disease, is known to increase the risk of developing T2MD, hypertension, dyslipidemias, CVDs, NAFLD, and other diseases, leading to a poor quality of life and increased mortality (167). Obesity is considered to be related to increased appetite, changes in the levels of gastrointestinal hormones, increased fat mass, and disorders of satiety and satiation mechanisms (168). A recent trial on the treatment effect of 
semaglutide in people with obesity reported the significant effects of the long-acting GLP-1RA semaglutide on body weight and related phenotypes (169). Besides, it was found that semaglutide could regulate food preference, as well as reduce food intake and weight without reducing energy consumption (170).

A randomized controlled trial found that GLP-1 mimics, such as exenatide and liraglutide, had a significant weight loss effect on obese/overweight patients without diabetes (171). Likewise, once a week administration of efpeglenatide, a long acting GLP-1RA, significantly reduced the body weight in obese patients (172). Interestingly, supplementation of metformin with $1.5 \mathrm{mg}$ dulaglutide per week in the treatment of T2MD in obese patients with severe impairment of glycosylated hemoglobin Alc (HbAlc) was reported to bring lasting benefits in the control of glucose metabolism and body weight (173). Moreover, there was no difference in weight changes between exenatide and abiglutide, and both were shown to exhibit remarkable weight loss effects (174). The GLP-1RAs-associated weight loss is thought to be achieved through a variety of mechanisms, including the delayed gastric emptying, increased satiety, increased resting energy expenditure, as well as the direct influence of the appetite center of the brain (175).

As GLP-1Rs are expressed in multiple brain regions, and GLP1RAs such as liraglutide and lixisenatide can penetrate the bloodbrain barrier, liraglutide and exendin- 4 can be vagus-dependent or independent in the suppression of the food intake (176). Semaglutide is considered to control energy intake and reduce body weight probably by activating at discrete sites in the hypothalamus to reduce food craving, or by delaying the gastric emptying to affect appetite $(119,177,178)$. In addition, GLP-1RAs could adjust the levels of the satiety signal in the arcuate nucleus in the hypothalamus, thereby increasing satiety and reducing caloric intake (179). Various studies have found that GLP-1RAs can play a role in controlling obesity through a variety of signaling pathways $(180,181)$. For example, they have been shown to activate the Wnt signaling pathway to promote adipocyte differentiation; while they could also rely on SIRT1 to mediate lipolysis and fatty acid oxidation in adipose tissues. When GLP-1RAs act on the gastrointestinal tract, they could extend the gastric emptying time. However, inhibiting gastric emptying mainly plays a role in reducing postprandial hyperglycaemia, and hence might not be the main mechanism of weight loss (176). In addition, GLP-1RAs could also increase energy consumption. Under the regulation of AMPK in the ventral medial hypothalamus, they could promote the conversion of visceral white adipose tissue (WAT) to brown adipose tissue (BAT), promoting thermogenesis of BAT and thus energy consumption (182). Finally, most patients could develop a tolerance mechanism to reduce or eliminate the GLP-1RAs-induced adverse reactions (182), thus allowing their use as drugs of choice for the treatment of obesity.

\section{EFFECTS ON NON-ALCOHOLIC FATTY LIVER DISEASE}

Non-alcoholic fatty liver disease (NAFLD) is a metabolic stress liver injury closely related to IR and genetic variations. It is also known to be closely related to the T2MD metabolic syndrome, and the morbidity and mortality of CVDs $(183,184)$. About $10 \%-25 \%$ of patients with NAFLD will develop non-alcoholic steatohepatitis (NASH), which increases the risk of liver cirrhosis or liver cancer (185). A number of studies has suggested that IR might be the main mechanism of NAFLD $(185,186)$. Moreover, the increased morbidity and mortality in patients with NASH is known to be closely related to the severity of liver fibrosis. It has been shown that an increased percentage of fat, adipose tissue dysfunction, and IR lead to increased levels of FFAs and carbohydrates. These conditions of excessive lipid toxicity and metabolic load eventually lead to the accumulation of liver lipids, cell damage, inflammation, and fibrosis $(187,188)$.

A prospective study found (189) that 1 year after bariatric surgery, NASH was eliminated in $85 \%$ of patients, indicating that weight loss was closely related to the histological improvement of fatty liver. Oxidative stress also seems to be an important pathophysiological mechanism of NAFLD (190).

As mentioned above, GLP-1RAs possess multiple biological effects, such as lowering the levels of blood glucose and blood lipids, reducing body weight, and protecting the cardiovascular system. A previous study of liraglutide on mice fed a diet lacking methionine and choline also found that GLP-1RAs not only could improve IR, but also reduce harmful ceramide/nerve sheath types, and reduce NAFLD inflammation and fibrosis (191). Liraglutide could also improve hepatic steatosis and ballooning degeneration in patients with NASH (192). A 72week, double-blind phase 2 trial showed that once-daily administration of semaglutide had a significant therapeutic effect on NASH (193). Long term use of beinaglutide, a recombinant human GLP-1(7-36) acid, was demonstrated to reduce the body weight and improve steatosis (194). Several studies found that GLP-1RAs might have direct effects on adipogenesis, lipotoxicity, fatty acid oxidation, cytokines related to hepatitis and fibrosis, and intestinal microbiota (193, 195). Therefore, GLP-1RAs are of great significance in the treatment of NAFLD.

As mentioned, GLP-1RAs can treat NAFLD through multiple mechanisms. Adiponectin was reported to reduce NAFLD inflammation through the AMPK-JNK/ErK1/2-NFKB/ROS signaling pathway, also exhibiting insulin sensitization and liver protection (196). A recent report covered that tirzepatide increased adiponectin levels and significantly decreased Nash related biomarkers, which was beneficial to improve NAFLD (197). In NAFLD mice, liraglutide could improve the hypoadiponectinemiainduced inflammatory stress by inhibiting the MKK4/JNK signaling pathway, inhibit liver adipogenesis by activating AMPK, and induce autophagy through the AMPK/mTOR pathway, hence improving the levels of liver lipids $(23,198)$. Further studies have shown that the SIRT1/HSF1/HSP pathway plays an important role in the exenatideinduced reduction of lipid-induced liver endoplasmic reticulum stress $(199,200)$. Concomitantly, autophagy was reported to also reduce the hepatocyte apoptosis caused by steatosis and endoplasmic reticulum stress, possibly through the GLP-1RA-stimulated GLP1R-mediated activation of the EB transcription factor of the autophagy-lysosome pathway, thus reducing the accumulation of 
liver lipids (201). Therefore, GLP-1RAs appear to serve as novel candidates for the treatment of NAFLD.

\section{EFFECTS OF GLUCAGON LIKE PEPTIDE-1 RECEPTOR AGONISTS ON TUMOR DISEASES}

To date, a large number of epidemiological investigations have confirmed that the occurrence of endometrial cancer, hepatobiliary cancer, pancreatic cancer, breast cancer, prostate cancer, and colorectal cancer is positively correlated with T2MD $(202,203)$. In addition, hyperinsulinemia in diabetic patients seems to be the main reason for an increased risk of cancer (204). Figure 5 illustrates the effect of diabetes on the tumor cell microenvironment and intracellular signaling transduction. The high levels of insulin have been shown to reduce the levels of the Insulin-like growth factor (IGF) binding protein, which can tightly bind to IGFs, resulting in excessive free IGF-1 in cells and tissues. In turn, the levels of IGF-1 have been shown to be associated with an increased risk of cancer $(204,205)$. Therefore, patients with T2MD are more likely to suffer from several malignancies compared with healthy individuals. However, selecting the right drug for the treatment of diabetic patients with malignancies is a difficult clinical decision. As mentioned, GLP-1RAs are increasingly used in the treatment of T2MD owing to their following advantages: lowering of the levels of blood glucose, reducing body weight, improving the function of islet, and exerting potential cardiovascular benefits (206). Whether GLP-1RAs could also affect the occurrence and development of tumors has been the focus of attention only in recent years.

A meta-analysis of clinical studies indicated that treatment with GLP-1RAs of obese patients with T2MD did not increase the risk of breast tumors, nor did it increase the risk of acute pancreatitis, pancreatic cancer, and overall tumor neoplasia (207-209). Furthermore, Gier et al. found that the use of GLP1RAs in diabetic patients might not increase the risk of new thyroid tumors in patients with T2MD (208). Related studies have found that GLP-1RAs could limit the growth of prostate cancer by inhibiting the PI3K/AKT/mTOR and ERK/MAPK pathways, while could also limit the growth of pancreatic and prostate cancer cells by inhibiting the NF-kB pathway (210-212). Similarly, GLP-1RAs were also demonstrated to exert an inhibitory effect on the growth of breast and cervical cancer, implying the potential application of GLP-1RAs for the treatment of these cancer (10). Zhang et al. reported for the first time that liraglutide exhibited significant anti-proliferation and pro-apoptotic effects on gemcitabine-resistant human pancreatic cancer cells resistant to a variety of drugs, by regulating the NF- $\mathrm{\kappa B}$ signaling pathway and downstream ATP-binding cassette subfamily G member 2 (ABCG2) $(213,214)$.

Likewise, Wenjing et al. found that exendin- 4 could reduce the resistance of prostate cancer cells to enzalutamide by targeting the PI3K/AKT/mTOR pathway, while combined use of exendin-4 and enzalutamide could significantly inhibit the growth of prostate cancer cells (210). Therefore, a combination of GLP-1RAs with anticancer drugs could indirectly inhibit the migration, invasion, and growth of tumors by increasing the chemosensitivity of cancer cells. Interestingly, this approach

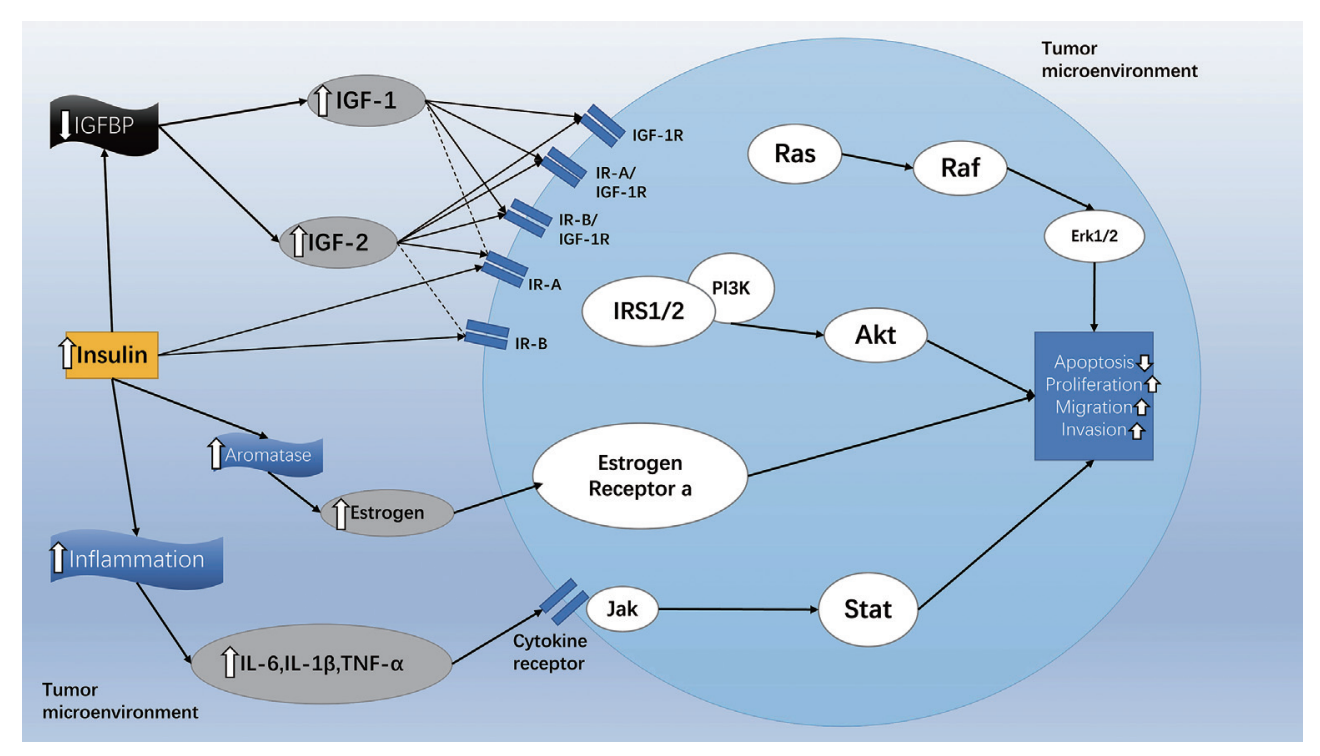

FIGURE 5 | The effect of diabetes on tumor cell microenvironment and intracellular signaling transduction. Diabetic patients can increase their levels of insulin and stimulate the PI3K/Akt/mTOR, Ras/Raf/MAPK, and Jak/Stat signaling pathways in different ways, thereby inhibiting cancer cell apoptosis and promoting the spread, migration, and invasion of cancer cells. Solid arrows indicate strong affinity for the receptor, and dashed arrows represent weak affinity for the receptor. The figure is modified from Ref 204. 
seems to be more effective for the treatment of patients with advanced cancer $(210,215)$.

Liraglutide and exenatide were reported to induce apoptosis and autophagy through the AMPK signaling pathway, inhibiting the progression of endometrial cancer $(216,217)$. In addition, exenatide was shown to activate GLP-1R and inhibit the PI3K/ AKT pathway to inhibit the growth, migration, and invasion of ovarian cancer cells, and promote cell apoptosis, thereby producing anticancer effects on diabetic patients with ovarian cancer (218). Besides, exenatide-4 has been found to inhibit the survival, migration, proliferation, and invasion of glioma cells in a GLP-1R/SIRT3 pathway dependent manner (219). The continuous in-depth research on the effects of GLP-1RAs on the occurrence and development of cancer in recent years have highlighted the increased potential for their use in the clinical treatment of cancer.

Unfortunately, the occurrence of some adverse events has caused deep concern about the long-term safety of GLP-1RAs. A population-based matched case (220) controlled study found that the treatment of patient with T2MD with exenatide might increase the chance of hospitalization for acute pancreatitis. In addition, Knapen (221) also found that the use of incretin drugs could increase the risk of pancreatic cancer by 1.7 times. However, because of the limited statistical power, insufficient follow-up time, and confusion about the severity of the disease, the researchers could not effectively conclude whether a direct relationship existed between the use of exenatide and the occurrence of acute pancreatitis. On the contrary, a systematic review on mortality, as well as cardiovascular and kidney statuses in patients with T2DM treated with GLP-1RAs concluded that there was no increase in the incidence of severe hypoglycaemia, pancreatitis, or pancreatic cancer (222). Cao (11) conducted a meta-analysis of 7 cardiovascular follow-up test results and discovered that the use of GLP-RAs was not correlated with the increased risk of pancreatic cancer. In contrast, they considered that obesity might be a risk factor for the development of pancreatitis and pancreatic cancer (223). Through rigorous scientific experiments, Zhao et al. showed that the activation of GLP-1R by liraglutide led to an anti-tumor effect on human pancreatic cancer via the inhibition of the PI3K/ AKT pathway (224). In addition, a large-scale clinical study demonstrated that GLP-1 analogues could reduce the mortality of patients with prostate cancer and diabetes (19). Conclusively, with regard to patients with pancreatic cancer and diabetes, GLP1RAs have the potential to treat pancreatic cancer while also controlling the levels of blood glucose $(210,224)$. A study on whether and how the activation of GLP-1R affects proliferation and apoptosis of human pancreatic cancer cells has demonstrated that GLP-1RAs might activate cAMP in a GLP1R-dependent manner, subsequently inhibiting the AKT and ERK1/2 signaling pathways, hence inhibiting the growth of transplanted tumors in vivo, as well as inducing apoptosis and inhibiting the proliferation of a human pancreatic cancer cell line in vitro (225). All the aforementioned results have suggested that GLP-1RAs are safe and beneficial for the treatment of pancreatitis and pancreatic cancer.
To date, no clear clinical evidence has been found to suggest the tumorigenic effect of GLP-1RAs (226), whereas plenty of studies have indicated that GLP-1RAs can inhibit the growth of ovarian, breast, prostate, and pancreatic cancer (227, 228). However, our understanding of the function of GLP-1RAs is not complete, and further research, including long-term and large clinical trials are warranted to properly evaluate the causal relationship between GLP-1RAs and the development and progression of various cancers.

\section{CONCLUSIONS AND FUTURE PERSPECTIVES}

Overall, GLP-1RAs are considered novel blood glucose lowering drugs used in the treatment of T2MD (229), owing to their advantages of lowering blood pressure, lowering the levels of fasting blood glucose, lowering $\mathrm{HbAlc}$, inducing weight loss, and being associated with a low incidence of hypoglycemia. In addition, GLP-1RAs are valuable in the treatment and prevention of diseases of the nervous and cardiovascular system, endocrine disorders, or metabolic diseases due to their neuroprotective, cardiovascular protective, and metabolic regulatory effects. However, there are still many controversies regarding the tolerability and adverse reactions of GLP-1RAs in the treatment of diabetes. Almost all diseases and drug treatments are inevitably associated with side effects, such as nausea and vomiting. Surprisingly though, a second-generation GLP-1RA conjugate composed of vitamin B12 and exendin-4 was reported to reduce the adverse reactions, exhibiting improved tolerance (230). Another imminent problem is that the GLP-1RAs that are currently used in the clinical setting are biological macromolecular peptide preparations, such as exenatide and liraglutide, with high production costs that limit their clinical application (231). One obvious advantage of the small molecule agonists in the replacement of peptide GLP-1 analogues is that they could be administered orally, thus avoiding the discomfort of subcutaneous injections and increasing the compliance of patients. Nowadays, LY3502790 and PF-06882961 (231-233), a class of oral non-peptide small molecule GLP-1RAs with preferable efficacy and anti-diabetes potential, are at the stage of pre-clinical research. Such developments are expected to greatly increase the confidence of patients regarding the improved efficiency and tolerance of GLP-1RAs. Therefore, we believe that the discovery of low-cost oral GLP-1RA analogues or synergists and the continuous elucidation of the possible mechanism of action of GLP-1 are of great significance for the expansion of the field of disease treatment.

\section{OUTSTANDING QUESTIONS}

GLP-1RA is a new type of drug for the treatment of T2MD. Recent studies have found that GLP-1RAs have therapeutic effects on neurological, cardiovascular, endocrine and metabolic diseases. More and more studies are looking for oral 
GLP-1RA analogs or synergists to enhance its therapeutic effect. This article systematically summarizes the extra-pancreatic effects of GLP-1RAs, and discusses the therapeutic effects and possible mechanisms of GLP-1RAs on various diseases. We believe that this article is of great significance to the research field and can provide ideas and directions for follow-up research.

\section{SEARCH STRATEGY AND SELECTION CRITERIA}

Data for this Review were identified by searches of MEDLINE, Current Contents, PubMed, and references from relevant articles using the search terms "GLP-1", "cardiovascular", "neurological", "endocrine" and "cancer". Abstracts and reports from meetings were included only when they related directly to previously published work. Only articles published in English between 1980 and 2021 were included.

\section{REFERENCES}

1. Graaf Cd, Donnelly D, Wootten D, Lau J, Sexton PM, Miller LJ, et al. GlucagonLike Peptide-1 and Its Class B G Protein-Coupled Receptors: A Long March to Therapeutic Successes. Pharmacol Rev (2016) 68(4):954-1013. doi: 10.1124/ pr.115.011395

2. Nauck MA, Quast DR, Wefers J, Meier JJ. GLP-1 Receptor Agonists in the Treatment of Type 2 Diabetes - State-of-the-Art. Mol Metab (2021) 46:101102. doi: 10.1016/j.molmet.2020.101102

3. Drucker DJ. Mechanisms of Action and Therapeutic Application of Glucagon-Like Peptide-1. Cell Metab (2018) 27(4):740-56. doi: 10.1016/j.cmet.2018.03.001

4. Isaacs D, Prasad-Reddy L, Srivastava SB. Role of Glucagon-Like Peptide 1 Receptor Agonists in Management of Obesity. Am J Health Syst Pharm (2016) 73(19):1493-507. doi: 10.2146/ajhp150990

5. Hirsch IB. The Future of the GLP-1 Receptor Agonists. JAMA (2019) 321 (15):1457-8. doi: 10.1001/jama.2019.2941

6. Wen S, Nguyen T, Gong M, Yuan X, Wang C, Jin J, et al. An Overview of Similarities and Differences in Metabolic Actions and Effects of Central Nervous System Between Glucagon-Like Peptide-1 Receptor Agonists (GLP1ras) and Sodium Glucose Co-Transporter-2 Inhibitors (SGLT-2is). Diabetes Metab Syndr Obes (2021) 14:2955-72. doi: 10.2147/DMSO.S312527

7. Bakbak E, Terenzi DC, Trac JZ, Teoh H, Quan A, Glazer SA, et al. Lessons From Bariatric Surgery: Can Increased GLP-1 Enhance Vascular Repair During Cardiometabolic-Based Chronic Disease? Rev Endocr Metab Disord (2021). doi: 10.1007/s11154-021-09669-7

8. Grieco M, Giorgi A, Gentile MC, d'Erme M, Morano S, Maras B, et al. Glucagon-Like Peptide-1: A Focus on Neurodegenerative Diseases. Front Neurosci (2019) 13:1112. doi: 10.3389/fnins.2019.01112

9. Gao H, Zeng Z, Zhang H, Zhou X, Guan L, Deng W, et al. The GlucagonLike Peptide-1 Analogue Liraglutide Inhibits Oxidative Stress and Inflammatory Response in the Liver of Rats With Diet-Induced NonAlcoholic Fatty Liver Disease. Biol Pharm Bull (2015) 38(5):694-702. doi: 10.1248/bpb.b14-00505

10. Mao D, Cao H, Shi M, Wang CC, Kwong J, Li JJX, et al. Increased CoExpression of PSMA2 and GLP-1 Receptor in Cervical Cancer Models in Type 2 Diabetes Attenuated by Exendin-4: A Translational Case-Control Study. EBioMedicine (2021) 65:103242. doi: 10.1016/j.ebiom.2021.103242

11. Cao C, Yang S, Zhou Z. GLP-1 Receptor Agonists and Pancreatic Safety Concerns in Type 2 Diabetic Patients: Data From Cardiovascular Outcome Trials. Endocrine (2020) 68(3):518-25. doi: 10.1007/s12020-020-02223-6

12. Brown JC, Dryburgh JR, Ross SA, Dupré J. Identification and Actions of Gastric Inhibitory Polypeptide. Recent Prog Horm Res (1975) 31:487-532. doi: 10.1016/b978-0-12-571131-9.50017-7

\section{AUTHOR CONTRIBUTIONS}

$\mathrm{XZ}$ and MW mainly wrote and revised the manuscripts, and constructed the framework of the manuscript. LC and CF provided constructive opinions on the formation of the manuscript. ZL, ZW, HX, and YL participated in the drawing of manuscript pictures and the investigation and sorting of documents. YZ participated in topic design, manuscript writing, manuscript editing and providing instructional support. All authors contributed to the article and approved the submitted version.

\section{FUNDING}

This work was supported by NSFC $(81770776 ; 81973378$, 82073909), Cultivate Scientific Research Excellence Programs of Higher Education Institutions in Shanxi (2019KJ022).This research project was supported by FSKSC and 1331KSC.

13. Bell GI, Sanchez-Pescador R, Laybourn PJ, Najarian RC. Exon Duplication and Divergence in the Human Preproglucagon Gene. Nature (1983) 304 (5924):368-71. doi: 10.1038/304368a0

14. Hansen L, Deacon CF, Orskov C, Holst JJ. Glucagon-Like Peptide-1-(7-36) Amide is Transformed to Glucagon-Like Peptide-1-(9-36)Amide by Dipeptidyl Peptidase IV in the Capillaries Supplying the L Cells of the Porcine Intestine. Endocrinology (1999) 140(11):5356-63. doi: 10.1210/ endo.140.11.7143

15. Meier JJ, Nauck MA, Kranz D, Holst JJ, Deacon CF, Gaeckler D, et al. Secretion, Degradation, and Elimination of Glucagon-Like Peptide 1 and Gastric Inhibitory Polypeptide in Patients With Chronic Renal Insufficiency and Healthy Control Subjects. Diabetes (2004) 53(3):654-62. doi: 10.2337/ diabetes.53.3.654

16. Elliott RM, Morgan LM, Tredger JA, Deacon S, Wright J, Marks V. GlucagonLike Peptide-1 (7-36)Amide and Glucose-Dependent Insulinotropic Polypeptide Secretion in Response to Nutrient Ingestion in Man: Acute Post-Prandial and 24-H Secretion Patterns. J Endocrinol (1993) 138(1):15966. doi: 10.1677/joe.0.1380159

17. Sharma D, Verma S, Vaidya S, Kalia K, Tiwari V. Recent Updates on GLP-1 Agonists: Current Advancements \& Challenges. BioMed Pharmacother. (2018) 108:952-62. doi: 10.1016/j.biopha.2018.08.088

18. Meier JJ. GLP-1 Receptor Agonists for Individualized Treatment of Type 2 Diabetes Mellitus. Nat Rev Endocrinol (2012) 8(12):728-42. doi: 10.1038/ nrendo.2012.140

19. Marso SP, Daniels GH, Brown-Frandsen K, Kristensen P, Mann JF, Nauck MA, et al. LEADER Steering Committee; LEADER Trial Investigators. Liraglutide and Cardiovascular Outcomes in Type 2 Diabetes. $N$ Engl J Med (2016) 375(4):311-22. doi: 10.1056/NEJMoa1603827

20. American Diabetes Association. 8. Pharmacologic Approaches to Glycemic Treatment: Standards of Medical Care in Diabetes-2018. Diabetes Care (2018) 41(Suppl 1):S73-85. doi: 10.2337/dc18-S008

21. Shi L, Ji Y, Jiang X, Zhou L, Xu Y, Li Y, et al. Liraglutide Attenuates High Glucose-Induced Abnormal Cell Migration, Proliferation, and Apoptosis of Vascular Smooth Muscle Cells by Activating the GLP-1 Receptor, and Inhibiting ERK1/2 and PI3K/Akt Signaling Pathways. Cardiovasc Diabetol (2015) 14:18. doi: 10.1186/s12933-015-0177-4

22. Lv X, Dong Y, Hu L, Lu F, Zhou C, Qin S. Glucagon-Like Peptide-1 Receptor Agonists (GLP-1 RAs) for the Management of Nonalcoholic Fatty Liver Disease (NAFLD): A Systematic Review. Endocrinol Diabetes Metab (2020) 3(3):e00163. doi: 10.1002/edm2.163

23. Zhang L, Yang M, Ren H, Hu H, Boden G, Li L, et al. GLP-1 Analogue Prevents NAFLD in ApoE KO Mice With Diet and Acrp30 Knockdown by Inhibiting C-JNK. Liver Int (2013) 33(5):794-804. doi: 10.1111/liv.12120 
24. Rasmussen CB, Lindenberg S. The Effect of Liraglutide on Weight Loss in Women With Polycystic Ovary Syndrome: An Observational Study. Front Endocrinol (Lausanne) (2014) 5:140. doi: 10.3389/fendo.2014.00140

25. Li Y, Duffy KB, Ottinger MA, Ray B, Bailey JA, Holloway HW, et al. GLP-1 Receptor Stimulation Reduces Amyloid-Beta Peptide Accumulation and Cytotoxicity in Cellular and Animal Models of Alzheimer's Disease. J Alzheimers Dis (2010) 19(4):1205-19. doi: 10.3233/JAD-2010-1314

26. Li Y, Perry T, Kindy MS, Harvey BK, Tweedie D, Holloway HW, et al. GLP-1 Receptor Stimulation Preserves Primary Cortical and Dopaminergic Neurons in Cellular and Rodent Models of Stroke and Parkinsonism. Proc Natl Acad Sci U S A (2009) 106(4):1285-90. doi: 10.1073/pnas.0806720106

27. Hölscher C. Central Effects of GLP-1: New Opportunities for Treatments of Neurodegenerative Diseases. J Endocrinol (2014) 221(1):T31-41. doi: 10.1530/ JOE-13-0221

28. Pyke C, Heller RS, Kirk RK, Ørskov C, Reedtz-Runge S, Kaastrup P, et al. GLP-1 Receptor Localization in Monkey and Human Tissue: Novel Distribution Revealed With Extensively Validated Monoclonal Antibody. Endocrinology (2014) 155(4):1280-90. doi: 10.1210/en.2013-1934

29. Muscogiuri G, DeFronzo RA, Gastaldelli A, Holst JJ. Glucagon-Like Peptide-1 and the Central/Peripheral Nervous System: Crosstalk in Diabetes. Trends Endocrinol Metab (2017) 28(2):88-103. doi: 10.1016/j.tem.2016.10.001

30. During MJ, Cao L, Zuzga DS, Francis JS, Fitzsimons HL, Jiao X, et al. Glucagon-Like Peptide-1 Receptor Is Involved in Learning and Neuroprotection. Nat Med (2003) 9(9):1173-9. doi: 10.1038/nm919

31. Salcedo I, Tweedie D, Li Y, Greig NH. Neuroprotective and Neurotrophic Actions of Glucagon-Like Peptide-1: An Emerging Opportunity to Treat Neurodegenerative and Cerebrovascular Disorders. Br J Pharmacol (2012) 166 (5):1586-99. doi: 10.1111/j.1476-5381.2012.01971.x

32. Isacson R, Nielsen E, Dannaeus K, Bertilsson G, Patrone C, Zachrisson O, et al. The Glucagon-Like Peptide 1 Receptor Agonist Exendin-4 Improves Reference Memory Performance and Decreases Immobility in the Forced Swim Test. Eur J Pharmacol (2011) 650(1):249-55. doi: 10.1016/j.ejphar.2010.10.008

33. Bertilsson G, Patrone C, Zachrisson O, Andersson A, Dannaeus K, Heidrich J, et al. Peptide Hormone Exendin-4 Stimulates Subventricular Zone Neurogenesis in the Adult Rodent Brain and Induces Recovery in an Animal Model of Parkinson's Disease. J Neurosci Res (2008) 86(2):326-38. doi: 10.1002/jnr.21483

34. Hamilton A, Patterson S, Porter D, Gault VA, Holscher C. Novel GLP-1 Mimetics Developed to Treat Type 2 Diabetes Promote Progenitor Cell Proliferation in the Brain. J Neurosci Res (2011) 89(4):481-9. doi: 10.1002/ jnr.22565

35. McClean PL, Parthsarathy V, Faivre E, Hölscher C. The Diabetes Drug Liraglutide Prevents Degenerative Processes in a Mouse Model of Alzheimer's Disease. J Neurosci (2011) 31(17):6587-94. doi: 10.1523/ JNEUROSCI.0529-11.2011

36. Makin S. The Amyloid Hypothesis on Trial. Nature (2018) 559(7715):S4-7. doi: 10.1038/d41586-018-05719-4

37. Serý O, Povová J, Míšek I, Pešák L, Janout V. Molecular Mechanisms of Neuropathological Changes in Alzheimer's Disease: A Review. Folia Neuropathol (2013) 51(1):1-9. doi: 10.5114/fn.2013.34190

38. Gallardo G, Holtzman DM. Amyloid- $\beta$ and Tau at the Crossroads of Alzheimer's Disease. Adv Exp Med Biol (2019) 1184:187-203. doi: 10.1007/ 978-981-32-9358-8_16

39. Ricciarelli R, Fedele E. The Amyloid Cascade Hypothesis in Alzheimer's Disease: It's Time to Change Our Mind. Curr Neuropharmacol (2017) 15 (6):926-35. doi: 10.2174/1570159X15666170116143743

40. Ubhi K, Masliah E. Alzheimer's Disease: Recent Advances and Future Perspectives. J Alzheimers Dis (2013) 33 Suppl 1:S185-94. doi: 10.3233/ JAD-2012-129028

41. Calsolaro V, Edison P. Neuroinflammation in Alzheimer's Disease: Current Evidence and Future Directions. Alzheimers Dement (2016) 12(6):719-32. doi: 10.1016/j.jalz.2016.02.010

42. Ott A, Stolk RP, van Harskamp F, Pols HA, Hofman A, Breteler MM. Diabetes Mellitus and the Risk of Dementia: The Rotterdam Study. Neurology (1999) 53 (9):1937-42. doi: 10.1212/wnl.53.9.1937

43. Yildirim Simsir I, Soyaltin UE, Cetinkalp S. Glucagon Like Peptide-1 (GLP-1) Likes Alzheimer's Disease. Diabetes Metab Syndr (2018) 12(3):469-75. doi: 10.1016/j.dsx.2018.03.002
44. McClean PL, Hölscher C. Liraglutide Can Reverse Memory Impairment, Synaptic Loss and Reduce Plaque Load in Aged APP/PS1 Mice, a Model of Alzheimer's Disease. Neuropharmacology (2014) 76:57-67. doi: 10.1016/ j.neuropharm.2013.08.005

45. Kim S, Moon M, Park S. Exendin-4 Protects Dopaminergic Neurons by Inhibition of Microglial Activation and Matrix Metalloproteinase-3 Expression in an Animal Model of Parkinson's Disease. J Endocrinol (2009) 202(3):431-9. doi: 10.1677/JOE-09-0132

46. Gilman CP, Perry T, Furukawa K, Grieg NH, Egan JM, Mattson MP. Glucagon-Like Peptide 1 Modulates Calcium Responses to Glutamate and Membrane Depolarization in Hippocampal Neurons. J Neurochem (2003) 87 (5):1137-44. doi: 10.1046/j.1471-4159.2003.02073.x

47. Chang YF, Zhang D, Hu WM, Liu DX, Li L. Semaglutide-Mediated Protection Against $A \beta$ Correlated With Enhancement of Autophagy and Inhibition of Apotosis. J Clin Neurosci (2020) 81:234-9. doi: 10.1016/j.jocn.2020.09.054

48. Zhou M, Chen S, Peng P, Gu Z, Yu J, Zhao G, et al. Dulaglutide Ameliorates STZ Induced AD-Like Impairment of Learning and Memory Ability by Modulating Hyperphosphorylation of Tau and NFs Through GSK3 3 . Biochem Biophys Res Commun (2019) 511(1):154-60. doi: 10.1016/ j.bbrc.2019.01.103

49. Bomfim TR, Forny-Germano L, Sathler LB, Brito-Moreira J, Houzel JC, Decker H, et al. An Anti-Diabetes Agent Protects the Mouse Brain From Defective Insulin Signaling Caused by Alzheimer's Disease- Associated A $\beta$ Oligomers. J Clin Invest (2012) 122(4):1339-53. doi: 10.1172/JCI57256

50. Wiciński M, Socha M, Malinowski B, Wódkiewicz E, Walczak M, Górski K, et al. Liraglutide and Its Neuroprotective Properties-Focus on Possible Biochemical Mechanisms in Alzheimer's Disease and Cerebral Ischemic Events. Int J Mol Sci (2019) 20(5):1050. doi: 10.3390/ijms20051050

51. Nishimoto I, Okamoto T, Matsuura Y, Takahashi S, Okamoto T, Murayama Y, et al. Alzheimer Amyloid Protein Precursor Complexes With Brain GTPBinding Protein G(o). Nature (1993) 362(6415):75-9. doi: 10.1038/ $362075 \mathrm{a} 0$

52. Han WN, Hölscher C, Yuan L, Yang W, Wang XH, Wu MN, et al. Liraglutide Protects Against Amyloid- $\beta$ Protein-Induced Impairment of Spatial Learning and Memory in Rats. Neurobiol Aging (2013) 34(2):576-88. doi: 10.1016/ j.neurobiolaging.2012.04.009

53. Kelly P, McClean PL, Ackermann M, Konerding MA, Hölscher C, Mitchell CA. Restoration of Cerebral and Systemic Microvascular Architecture in APP/ PS1 Transgenic Mice Following Treatment With Liraglutide ${ }^{\mathrm{TM}}$. Microcirculation (2015) 22(2):133-45. doi: 10.1111/micc.12186

54. Poewe W, Seppi K, Tanner CM, Halliday GM, Brundin P, Volkmann J, et al. Parkinson Disease. Nat Rev Dis Primers (2017) 3:17013. doi: 10.1038/ nrdp.2017.13

55. Kalia LV, Lang AE. Parkinson's Disease. Lancet (2015) 386(9996):896-912. doi: 10.1016/S0140-6736(14)61393-3

56. Armstrong MJ, Okun MS. Diagnosis and Treatment of Parkinson Disease: A Review. JAMA (2020) 323(6):548-60. doi: 10.1001/jama.2019.22360

57. Jankovic J, Tan EK. Parkinson's Disease: Etiopathogenesis and Treatment. J Neurol Neurosurg Psychiatry (2020) 91(8):795-808. doi: 10.1136/jnnp-2019322338

58. Koprich JB, Kalia LV, Brotchie JM. Animal Models of $\alpha$-Synucleinopathy for Parkinson Disease Drug Development. Nat Rev Neurosci (2017) 18(9):515-29. doi: 10.1038/nrn.2017.75

59. Ji C, Xue GF, Li G, Li D, Hölscher C. Neuroprotective Effects of GlucoseDependent Insulinotropic Polypeptide in Alzheimer's Disease. Rev Neurosci (2016) 27(1):61-70. doi: 10.1515/revneuro-2015-0021

60. Hölscher C. Insulin, Incretins and Other Growth Factors as Potential Novel Treatments for Alzheimer's and Parkinson's Diseases. Biochem Soc Trans (2014) 42(2):593-9. doi: 10.1042/BST20140016

61. Hölscher C. Novel Dual GLP-1/GIP Receptor Agonists Show Neuroprotective Effects in Alzheimer's and Parkinson's Disease Models. Neuropharmacology (2018) 136(Pt B):251-9. doi: 10.1016/j.neuropharm.2018.01.040

62. Victorino DB, Nejm M, Guimarães-Marques M, Scorza FA, Scorza CA. Repurposing GLP-1 Receptor Agonists for Parkinson's Disease: Current Evidence and Future Opportunities. Pharmaceut Med (2021) 35(1):11-9. doi: 10.1007/s40290-020-00374-5

63. Liu W, Jalewa J, Sharma M, Li G, Li L, Hölscher C. Neuroprotective Effects of Lixisenatide and Liraglutide in the 1-Methyl-4-Phenyl-1,2,3,6- 
Tetrahydropyridine Mouse Model of Parkinson's Disease. Neuroscience (2015) :303:42-50. doi: 10.1016/j.neuroscience.2015.06.054

64. Zhang L, Zhang L, Li L, Hölscher C. Semaglutide is Neuroprotective and Reduces $\alpha$-Synuclein Levels in the Chronic MPTP Mouse Model of Parkinson's Disease. J Parkinsons Dis (2019) 9(1):157-71. doi: 10.3233/JPD181503

65. Mulvaney CA, Duarte GS, Handley J, Evans DJ, Menon S, Wyse R, et al. GLP1 Receptor Agonists for Parkinson's Disease. Cochrane Database Syst Rev (2020) 7(7):CD012990. doi: 10.1002/14651858.CD012990.pub2

66. Chen Y, Zhang Y, Li L, Hölscher C. Neuroprotective Effects of Geniposide in the MPTP Mouse Model of Parkinson's Disease. Eur J Pharmacol (2015) 768:21-7. doi: 10.1016/j.ejphar.2015.09.029

67. Pajares M, Rojo A I, Manda G, Boscá L, Cuadrado A. Inflammation in Parkinson's Disease: Mechanisms and Therapeutic Implications. Cells (2020) 9(7):1687. doi: 10.3390/cells9071687

68. Bartels AL, Willemsen AT, Doorduin J, de Vries EF, Dierckx RA, Leenders KL. [11c]-PK11195 PET: Quantification of Neuroinflammation and a Monitor of Anti-Inflammatory Treatment in Parkinson's Disease? Parkinsonism Relat Disord (2010) 16(1):57-9. doi: 10.1016/ j.parkreldis.2009.05.005

69. Fan Z, Aman Y, Ahmed I, Chetelat G, Landeau B, Ray Chaudhuri K, et al. Influence of Microglial Activation on Neuronal Function in Alzheimer's and Parkinson's Disease Dementia. Alzheimers Dement (2015) 11(6):608-21.e7. doi: 10.1016/j.jalz.2014.06.016

70. Athauda D, Foltynie T. The Glucagon-Like Peptide 1 (GLP) Receptor as a Therapeutic Target in Parkinson's Disease: Mechanisms of Action. Drug Discovery Today (2016) 21(5):802-18. doi: 10.1016/j.drudis.2016.01.013

71. Bose A, Beal MF. Mitochondrial Dysfunction in Parkinson's Disease. J Neurochem (2016) 139:216-31. doi: 10.1111/jnc.13731

72. Nassar NN, Al-Shorbagy MY, Arab HH, Abdallah DM. Saxagliptin: A Novel Antiparkinsonian Approach. Neuropharmacology (2015) 89:308-17. doi: 10.1016/j.neuropharm.2014.10.007

73. Aviles-Olmos I, Dickson J, Kefalopoulou Z, Djamshidian A, Ell P, Soderlund $\mathrm{T}$, et al. Exenatide and the Treatment of Patients With Parkinson's Disease. J Clin Invest (2013) 123(6):2730-6. doi: 10.1172/JCI68295

74. Athauda D, Maclagan K, Skene SS, Bajwa-Joseph M, Letchford D, Chowdhury $\mathrm{K}$, et al. Exenatide Once Weekly Versus Placebo in Parkinson's Disease: A Randomised, Double-Blind, Placebo-Controlled Trial. Lancet (2017) 390 (10103):1664-75. doi: 10.1016/S0140-6736(17)31585-4

75. Zhang L, Zhang L, Li L, Hölscher C. Neuroprotective Effects of the Novel GLP-1 Long Acting Analogue Semaglutide in the MPTP Parkinson's Disease Mouse Model. Neuropeptides (2018) 71:70-80. doi: 10.1016/ j.npep.2018.07.003

76. Brauer R, Wei L, Ma T, Athauda D, Girges C, Vijiaratnam N, et al. Diabetes Medications and Risk of Parkinson's Disease: A Cohort Study of Patients With Diabetes. Brain (2020) 143(10):3067-76. doi: 10.1093/brain/awaa262

77. Hankey GJ, Blacker DJ. Is it a Stroke? BMJ (2015) 350:h56. doi: 10.1136/ bmj.h56

78. Hankey GJ. Stroke. Lancet (2017) 389(10069):641-54. doi: 10.1016/S01406736(16)30962-X

79. Roth GA, Forouzanfar MH, Moran AE, Barber R, Nguyen G, Feigin VL, et al. Demographic and Epidemiologic Drivers of Global Cardiovascular Mortality. N Engl J Med (2015) 372(14):1333-41. doi: 10.1056/ NEJMoa1406656

80. Darsalia V, Klein T, Nyström T, Patrone C. Glucagon-Like Receptor 1 Agonists and DPP-4 Inhibitors: Anti-Diabetic Drugs With Anti-Stroke Potential. Neuropharmacology (2018) 136(Pt B):280-6. doi: 10.1016/ j.neuropharm.2017.08.022

81. Huang J, Liu Y, Cheng L, Li J, Zhang T, Zhao G, et al. Glucagon-Like Peptide1 Cleavage Product GLP-1(9-36) Reduces Neuroinflammation From Stroke via the Activation of Insulin-Like Growth Factor 1 Receptor in Astrocytes. Eur J Pharmacol (2020) 887:173581. doi: 10.1016/j.ejphar.2020.173581

82. Teramoto S, Miyamoto N, Yatomi K, Tanaka Y, Oishi H, Arai H, et al. Exendin-4, a Glucagon-Like Peptide-1 Receptor Agonist, Provides Neuroprotection in Mice Transient Focal Cerebral Ischemia. J Cereb Blood Flow Metab (2011) 31(8):1696-705. doi: 10.1038/jcbfm.2011.51

83. Darsalia V, Larsson M, Nathanson D, Klein T, Nyström T, Patrone C. Glucagon-Like Receptor 1 Agonists and DPP-4 Inhibitors: Potential
Therapies for the Treatment of Stroke. J Cereb Blood Flow Metab (2015) 35 (5):718-23. doi: 10.1038/jcbfm.2015.17

84. Larsson M, Lietzau G, Nathanson D, Östenson CG, Mallard C, Johansson ME, et al. Diabetes Negatively Affects Cortical and Striatal GABAergic Neurons: An Effect That is Partially Counteracted by Exendin-4. Biosci Rep (2016) 36 (6):e00421. doi: 10.1042/BSR20160437

85. Zhang H, Meng J, Zhou S, Liu Y, Qu D, Wang L, et al. Intranasal Delivery of Exendin-4 Confers Neuroprotective Effect Against Cerebral Ischemia in Mice. AAPS J (2016) 18(2):385-94. doi: 10.1208/s12248-015-9854-1

86. Sato K, Kameda M, Yasuhara T, Agari T, Baba T, Wang F, et al. Neuroprotective Effects of Liraglutide for Stroke Model of Rats. Int J Mol Sci (2013) 14(11):21513-24. doi: 10.3390/ijms141121513

87. Zhu H, Zhang Y, Shi Z, Lu D, Li T, Ding Y, et al. The Neuroprotection of Liraglutide Against Ischaemia-Induced Apoptosis Through the Activation of the PI3K/AKT and MAPK Pathways. Sci Rep (2016) 6:26859. doi: 10.1038/ srep26859

88. Gerstein HC, Hart R, Colhoun HM, Diaz R, Lakshmanan M, Botros FT, et al. The Effect of Dulaglutide on Stroke: An Exploratory Analysis of the REWIND Trial. Lancet Diabetes Endocrinol (2020) 8(2):106-14. doi: 10.1016/S22138587(19)30423-1

89. Basalay MV, Davidson SM, Yellon DM. Neuroprotection in Rats Following Ischaemia-Reperfusion Injury by GLP-1 Analogues-Liraglutide and Semaglutide. Cardiovasc Drugs Ther (2019) 33(6):661-7. doi: 10.1007/ s10557-019-06915-8

90. Verma MK, Goel R, Krishnadas N, Nemmani KVS. Targeting GlucoseDependent Insulinotropic Polypeptide Receptor for Neurodegenerative Disorders. Expert Opin Ther Targets (2018) 22(7):615-28. doi: 10.1080/ 14728222.2018.1487952

91. Raja SN, Carr DB, Cohen M, Finnerup NB, Flor H, Gibson S, et al. The Revised International Association for the Study of Pain Definition of Pain: Concepts, Challenges, and Compromises. Pain (2020) 161(9):1976-82. doi: 10.1097/j.pain.0000000000001939

92. Ashburn MA, Staats PS. Management of Chronic Pain. Lancet (1999) 353 (9167):1865-9. doi: 10.1016/S0140-6736(99)04088-X

93. Chapman CR, Vierck CJ. The Transition of Acute Postoperative Pain to Chronic Pain: An Integrative Overview of Research on Mechanisms. J Pain (2017) 18(4):359.e1-359.e38. doi: 10.1016/j.jpain.2016.11.004

94. Hylands-White N, Duarte RV, Raphael JH. An Overview of Treatment Approaches for Chronic Pain Management. Rheumatol Int (2017) 37(1):2942. doi: 10.1007/s00296-016-3481-8

95. Bindu S, Mazumder S, Bandyopadhyay U. Non-Steroidal Anti-Inflammatory Drugs (NSAIDs) and Organ Damage: A Current Perspective. Biochem Pharmacol (2020) 180:114147. doi: 10.1016/j.bcp.2020.114147

96. Christie MJ. Cellular Neuroadaptations to Chronic Opioids: Tolerance, Withdrawal and Addiction. Br J Pharmacol (2008) 154(2):384-96. doi: $10.1038 /$ bjp. 2008.100

97. Webster LR, Reisfield GM, Dasgupta N. Eight Principles for Safer Opioid Prescribing and Cautions With Benzodiazepines. Postgrad Med (2015) 127 (1):27-32. doi: 10.1080/00325481.2015.993276

98. Gong N, Xiao Q, Zhu B, Zhang CY, Wang YC, Fan H, et al. Activation of Spinal Glucagon-Like Peptide-1 Receptors Specifically Suppresses Pain Hypersensitivity. J Neurosci (2014) 34(15):5322-34. doi: 10.1523/ JNEUROSCI.4703-13.2014

99. Gong N, Fan H, Ma AN, Xiao Q, Wang YX. Geniposide and Its Iridoid Analogs Exhibit Antinociception by Acting at the Spinal GLP-1 Receptors. Neuropharmacology (2014) 84:31-45. doi: 10.1016/j.neuropharm.2014.04.007

100. Cui SS, Feng XB, Zhang BH, Xia ZY, Zhan LY. Exendin-4 Attenuates PainInduced Cognitive Impairment by Alleviating Hippocampal Neuroinflammation in a Rat Model of Spinal Nerve Ligation. Neural Regener Res (2020) 15(7):1333-9. doi: 10.4103/1673-5374.272620

101. Hellström PM. GLP-1 Playing the Role of a Gut Regulatory Compound. Acta Physiol (Oxf) (2011) 201(1):151-6. doi: 10.1111/j.1748-1716.2010.02150.x

102. Nozu T, Miyagishi S, Kumei S, Nozu R, Takakusaki K, Okumura T. Glucagon-Like Peptide-1 Analog, Liraglutide, Improves Visceral Sensation and Gut Permeability in Rats. J Gastroenterol Hepatol (2018) 33(1):232-9. doi: $10.1111 /$ jgh. 13808

103. Wu HY, Tang XQ, Mao XF, Wang YX. Autocrine Interleukin-10 Mediates Glucagon-Like Peptide-1 Receptor-Induced Spinal Microglial $\beta$-Endorphin 
Expression. J Neurosci (2017) 37(48):11701-14. doi: 10.1523/ JNEUROSCI.1799-17.2017

104. Wu HY, Tang XQ, Liu H, Mao XF, Wang YX. Both Classic Gs-cAMP/PKA/ CREB and Alternative Gs-cAMP/PKA/P38//CREB Signal Pathways Mediate Exenatide-Stimulated Expression of M2 Microglial Markers. J Neuroimmunol (2018) 316:17-22. doi: 10.1016/j.jneuroim.2017.12.005

105. Wu HY, Mao XF, Fan H, Wang YX. P38ß Mitogen-Activated Protein Kinase Signaling Mediates Exenatide-Stimulated Microglial $\beta$-Endorphin Expression. Mol Pharmacol (2017) 91(5):451-63. doi: 10.1124/ mol.116.107102

106. Fan H, Gong N, Li TF, Ma AN, Wu XY, Wang MW, et al. The Non-Peptide GLP-1 Receptor Agonist WB4-24 Blocks Inflammatory Nociception by Stimulating $\beta$-Endorphin Release From Spinal Microglia. Br J Pharmacol (2015) 172(1):64-79. doi: 10.1111/bph.12895

107. Zhao D, Liu J, Wang M, Zhang X, Zhou M. Epidemiology of Cardiovascular Disease in China: Current Features and Implications. Nat Rev Cardiol (2019) 16(4):203-12. doi: 10.1038/s41569-018-0119-4

108. Heuvelman VD, Van Raalte DH, Smits MM. Cardiovascular Effects of Glucagon-Like Peptide 1 Receptor Agonists: From Mechanistic Studies in Humans to Clinical Outcomes. Cardiovasc Res (2020) 116(5):916-30. doi: $10.1093 / \mathrm{cvr} / \mathrm{cvz} 323$

109. Sharma A, Verma S. Mechanisms by Which Glucagon-Like-Peptide-1 Receptor Agonists and Sodium-Glucose Cotransporter-2 Inhibitors Reduce Cardiovascular Risk in Adults With Type 2 Diabetes Mellitus. Can J Diabetes (2020) 44(1):93-102. doi: 10.1016/j.jcjd.2019.09.003

110. Husain M, Birkenfeld AL, Donsmark M, Dungan K, Eliaschewitz FG, Franco DR, et al. PIONEER 6 Investigators. Oral Semaglutide and Cardiovascular Outcomes in Patients With Type 2 Diabetes. N Engl J Med (2019) 381 (9):841-51. doi: 10.1056/NEJMoa1901118

111. Helmstädter J, Frenis K, Filippou K, Grill A, Dib M, Kalinovic S, et al. Endothelial GLP-1 (Glucagon-Like Peptide-1) Receptor Mediates Cardiovascular Protection by Liraglutide In Mice With Experimental Arterial Hypertension. Arterioscler Thromb Vasc Biol (2020) 40(1):145-58. doi: $10.1161 /$ atv. 0000615456.97862 .30

112. Husain M, Bain SC, Jeppesen OK, Lingvay I, Sørrig R, Treppendahl MB, et al. Semaglutide (SUSTAIN and PIONEER) Reduces Cardiovascular Events in Type 2 Diabetes Across Varying Cardiovascular Risk. Diabetes Obes Metab (2020) 22(3):442-51. doi: 10.1111/dom.13955

113. Falk E. Pathogenesis of Atherosclerosis. J Am Coll Cardiol (2006) 47(8 Suppl):C7-12. doi: 10.1016/j.jacc.2005.09.068

114. Chang W, Zhu F, Zheng H, Zhou Z, Miao P, Zhao L, et al. Glucagon-Like Peptide-1 Receptor Agonist Dulaglutide Prevents Ox-LDL-Induced Adhesion of Monocytes to Human Endothelial Cells: An Implication in the Treatment of Atherosclerosis. Mol Immunol (2019) 116:73-9. doi: 10.1016/j.molimm.2019.09.021

115. Bourantas CV, Zanchin T, Sakellarios A, Karagiannis A, Ramasamy A, Yamaji K, et al. Implications of the Local Haemodynamic Forces on the Phenotype of Coronary Plaques. Heart (2019) 105(14):1078-86. doi: 10.1136/heartjnl-2018-314086

116. Lu H, Daugherty A. Atherosclerosis. Arterioscler Thromb Vasc Biol (2015) 35 (3):485-91. doi: 10.1161/ATVBAHA.115.305380

117. Knudsen LB, Lau J. The Discovery and Development of Liraglutide and Semaglutide. Front Endocrinol (Lausanne) (2019) 10:155. doi: 10.3389/ fendo.2019.00155

118. Ma X, Liu Z, Ilyas I, Little PJ, Kamato D, Sahebka A, et al. GLP-1 Receptor Agonists (GLP-1ras): Cardiovascular Actions and Therapeutic Potential. Int J Biol Sci (2021) 17(8):2050-68. doi: 10.7150/ijbs.59965

119. Hamal S, Cherukuri L, Shaikh K, Kinninger A, Doshi J, Birudaraju D, et al. Effect of Semaglutide on Coronary Atherosclerosis Progression in Patients With Type II Diabetes: Rationale and Design of the Semaglutide Treatment on Coronary Progression Trial. Coron Artery Dis (2020) 31(3):306-14. doi: 10.1097/MCA.0000000000000830

120. Goto H, Nomiyama T, Mita T, Yasunari E, Azuma K, Komiya K, et al. Exendin-4, a Glucagon-Like Peptide-1 Receptor Agonist, Reduces Intimal Thickening After Vascular Injury. Biochem Biophys Res Commun (2011) 405 (1):79-84. doi: 10.1016/j.bbrc.2010.12.131

121. Han Y, Liu W, Chen L, Xin X, Wang Q, Zhang X, et al. Effective Oral Delivery of Exenatide-Zn2+ Complex Through Distal Ileum-Targeted
Double Layers Nanocarriers Modified With Deoxycholic Acid and Glycocholic Acid in Diabetes Therapy. Biomaterials (2021) 275:120944. doi: 10.1016/j.biomaterials.2021.120944

122. Gaspari T, Liu H, Welungoda I, Hu Y, Widdop RE, Knudsen LB, et al. A GLP-1 Receptor Agonist Liraglutide Inhibits Endothelial Cell Dysfunction and Vascular Adhesion Molecule Expression in an ApoE-/- Mouse Model. Diabetes Vasc Dis Res (2011) 8(2):117-24. doi: 10.1177/1479164111404257 Erratum in: Diab Vasc Dis Res. 2012 Jan;9(1):79.

123. Drucker DJ. The Cardiovascular Biology of Glucagon-Like Peptide-1. Cell Metab (2016) 24(1):15-30. doi: 10.1016/j.cmet.2016.06.009

124. Verma S, McGuire DK, Bain SC, Bhatt DL, Leiter LA, Mazer CD, et al. Effects of Glucagon-Like Peptide-1 Receptor Agonists Liraglutide and Semaglutide on Cardiovascular and Renal Outcomes Across Body Mass Index Categories in Type 2 Diabetes: Results of the LEADER and SUSTAIN 6 Trials. Diabetes Obes Metab (2020) 22(12):2487-92. doi: 10.1111/dom.14160

125. Rakipovski G, Rolin B, Nøhr J, Klewe I, Frederiksen KS, Augustin R, et al. The GLP-1 Analogs Liraglutide and Semaglutide Reduce Atherosclerosis in ApoE-/- and LDLr-/- Mice by a Mechanism That Includes Inflammatory Pathways. JACC Basic Transl Sci (2018) 3(6):844-57. doi: 10.1016/ j.jacbts.2018.09.004

126. Rizzo M, Nikolic D, Patti AM, Mannina C, Montalto G, McAdams BS, et al. GLP-1 Receptor Agonists and Reduction of Cardiometabolic Risk: Potential Underlying Mechanisms. Biochim Biophys Acta Mol Basis Dis (2018) 1864(9 Pt B):2814-21. doi: 10.1016/j.bbadis.2018.05.012

127. Bruen R, Curley S, Kajani S, Crean D, O’Reilly ME, Lucitt MB, et al. Liraglutide Dictates Macrophage Phenotype in Apolipoprotein E Null Mice During Early Atherosclerosis. Cardiovasc Diabetol (2017) 16(1):143. doi: 10.1186/s12933-017-0626-3

128. Yue W, Li Y, Ou D, Yang Q. The GLP-1 Receptor Agonist Liraglutide Protects Against Oxidized LDL-Induced Endothelial Inflammation and Dysfunction via KLF2. IUBMB Life (2019) 71(9):1347-54. doi: 10.1002/ iub.2046

129. Vinue Á, Navarro J, Herrero-Cervera A, García-Cubas M, Andrés-Blasco I, Martínez-Hervás S, et al. The GLP-1 Analogue Lixisenatide Decreases Atherosclerosis in Insulin-Resistant Mice by Modulating Macrophage Phenotype. Diabetologia (2017) 60(9):1801-12. doi: 10.1007/s00125-0174330-3

130. Jojima T, Uchida K, Akimoto K, Tomotsune T, Yanagi K, Iijima T, et al. Liraglutide, a GLP-1 Receptor Agonist, Inhibits Vascular Smooth Muscle Cell Proliferation by Enhancing AMP-Activated Protein Kinase and Cell Cycle Regulation, and Delays Atherosclerosis in ApoE Deficient Mice. Atherosclerosis (2017) 261:44-51. doi: 10.1016/j.atherosclerosis. 2017.04.001

131. Poulter NR, Prabhakaran D, Caulfield M. Hypertension. Lancet (2015) 386 (9995):801-12. doi: 10.1016/S0140-6736(14)61468-9

132. Kim M, Platt MJ, Shibasaki T, Quaggin SE, Backx PH, Seino S, et al. GLP-1 Receptor Activation and Epac2 Link Atrial Natriuretic Peptide Secretion to Control of Blood Pressure. Nat Med (2013) 19(5):567-75. doi: 10.1038/ nm. 3128

133. GBD 2015 Risk Factors Collaborators. Global, Regional, and National Comparative Risk Assessment of 79 Behavioural, Environmental and Occupational, and Metabolic Risks or Clusters of Risks, 1990-2015: A Systematic Analysis for the Global Burden of Disease Study 2015. Lancet (2016) 388(10053):1659-724. doi: 10.1016/S0140-6736(16)31679-8 Erratum in: Lancet. 2017 Jan 7;389(10064):e1.

134. Oparil S, Acelajado MC, Bakris GL, Berlowitz DR, Cífková R, Dominiczak AF, et al. Hypertension. Nat Rev Dis Primers (2018) 4:18014. doi: 10.1038/ nrdp.2018.14

135. Campbell JE, Drucker DJ. Pharmacology, Physiology, and Mechanisms of Incretin Hormone Action. Cell Metab (2013) 17(6):819-37. doi: 10.1016/ j.cmet.2013.04.008

136. Wang B, Zhong J, Lin H, Zhao Z, Yan Z, He H, et al. Blood PressureLowering Effects of GLP-1 Receptor Agonists Exenatide and Liraglutide: A Meta-Analysis of Clinical Trials. Diabetes Obes Metab (2013) 15(8):737-49. doi: $10.1111 /$ dom. 12085

137. Ding L, Zhang J. Glucagon-Like Peptide-1 Activates Endothelial Nitric Oxide Synthase in Human Umbilical Vein Endothelial Cells. Acta Pharmacol Sin (2012) 33(1):75-81. doi: 10.1038/aps.2011.149 
138. Almutairi M, Al Batran R, Ussher JR. Glucagon-Like Peptide-1 Receptor Action in the Vasculature. Peptides (2019) 111:26-32. doi: 10.1016/ j.peptides.2018.09.002

139. Huang J, Zhao J, Geng X, Chu W, Li S, Chen ZJ, et al. Long non-Coding RNA lnc-CCNL1-3:1 Promotes Granulosa Cell Apoptosis and Suppresses Glucose Uptake in Women With Polycystic Ovary Syndrome. Mol Ther Nucleic Acids (2020) 23:614-28. doi: 10.1016/j.omtn.2020.12.008

140. Escobar-Morreale HF. Polycystic Ovary Syndrome: Definition, Aetiology, Diagnosis and Treatment. Nat Rev Endocrinol (2018) 14(5):270-84. doi: $10.1038 /$ nrendo.2018.24

141. Moran L, Teede H. Metabolic Features of the Reproductive Phenotypes of Polycystic Ovary Syndrome. Hum Reprod Update (2009) 15(4):477-88. doi: 10.1093/humupd/dmp008

142. Moran LJ, Tassone EC, Boyle J, Brennan L, Harrison CL, Hirschberg AL, et al. Evidence Summaries and Recommendations From the International Evidence-Based Guideline for the Assessment and Management of Polycystic Ovary Syndrome: Lifestyle Management. Obes Rev (2020) 21(10):e13046. doi: 10.1111/obr.13046

143. Setji TL, Brown AJ. Polycystic Ovary Syndrome: Update on Diagnosis and Treatment. Am J Med (2014) 127(10):912-9. doi: 10.1016/ j.amjmed.2014.04.017

144. Azziz R, Carmina E, Chen Z, Dunaif A, Laven JS, Legro RS, et al. Polycystic Ovary Syndrome. Nat Rev Dis Primers (2016) 2:16057. doi: 10.1038/ nrdp.2016.57

145. Astapova O, Minor BMN, Hammes SR. Physiological and Pathological Androgen Actions in the Ovary. Endocrinology (2019) 160(5):1166-74. doi: 10.1210/en.2019-00101

146. Rosenfield RL, Ehrmann DA. The Pathogenesis of Polycystic Ovary Syndrome (PCOS): The Hypothesis of PCOS as Functional Ovarian Hyperandrogenism Revisited. Endocr Rev (2016) 37(5):467-520. doi: 10.1210/er.2015-1104

147. Martínez-García MÁ, Moncayo S, Insenser M, Álvarez-Blasco F, LuqueRamírez M, Escobar-Morreale HF. Metabolic Cytokines at Fasting and During Macronutrient Challenges: Influence of Obesity, Female Androgen Excess and Sex. Nutrients (2019) 11(11):2566. doi: 10.3390/nu11112566

148. Yang F, Ruan YC, Yang YJ, Wang K, Liang SS, Han YB, et al. Follicular Hyperandrogenism Downregulates Aromatase in Luteinized Granulosa Cells in Polycystic Ovary Syndrome Women. Reproduction (2015) 150(4):289-96. doi: 10.1530/REP-15-0044

149. Ma X, Hayes E, Prizant H, Srivastava RK, Hammes SR, Sen A, et al. (Cocaine- and Amphetamine-Regulated Transcript) Is a Novel Intraovarian Mediator of Obesity-Related Infertility in Females. Endocrinology (2016) 157(3):1248-57. doi: 10.1210/en.2015-1750

150. Chow LS, Mashek DG, Wang Q, Shepherd SO, Goodpaster BH, Dubé JJ. Effect of Acute Physiological Free Fatty Acid Elevation in the Context of Hyperinsulinemia on Fiber Type-Specific IMCL Accumulation. J Appl Physiol (1985) (2017) 123(1):71-8. doi: 10.1152/japplphysiol.00209.2017

151. Pereira S, Park E, Moore J, Faubert B, Breen DM, Oprescu AI, et al. Resveratrol Prevents Insulin Resistance Caused by Short-Term Elevation of Free Fatty Acids In Vivo. Appl Physiol Nutr Metab (2015) 40(11):1129-36. doi: 10.1139/apnm-2015-0075

152. Bjekić-Macut J, Vukašin T, Velija-Ašimi Z, Bureković A, Zdravković M, Andrić Z, et al. Polycystic Ovary Syndrome: A Contemporary Clinical Approach. Curr Pharm Des (2021). doi: 10.2174/ 1381612827666210119104721 Epub ahead of print.

153. Malini NA, Roy George K. Evaluation of Different Ranges of LH : FSH Ratios in Polycystic Ovarian Syndrome (PCOS) - Clinical Based Case Control Study. Gen Comp Endocrinol (2018) 260:51-7. doi: 10.1016/j.ygcen.2017.12.007

154. Zeng X, Xie YJ, Liu YT, Long SL, Mo ZC. Polycystic Ovarian Syndrome: Correlation Between Hyperandrogenism, Insulin Resistance and Obesity. Clin Chim Acta (2020) 502:214-21. doi: 10.1016/j.cca.2019.11.003

155. De Leo V, la Marca A, Petraglia F. Insulin-Lowering Agents in the Management of Polycystic Ovary Syndrome. Endocr Rev (2003) 24 (5):633-67. doi: 10.1210/er.2002-0015

156. Lamos EM, Malek R, Davis SN. GLP-1 Receptor Agonists in the Treatment of Polycystic Ovary Syndrome. Expert Rev Clin Pharmacol (2017) 10(4):4018. doi: 10.1080/17512433.2017.1292125
157. Frøssing S, Nylander M, Chabanova E, Frystyk J, Holst JJ, Kistorp C, et al. Effect of Liraglutide on Ectopic Fat in Polycystic Ovary Syndrome: A Randomized Clinical Trial. Diabetes Obes Metab (2018) 20(1):215-8. doi: $10.1111 /$ dom. 13053

158. Jensterle M, Kravos NA, Goričar K, Janez A. Short-Term Effectiveness of Low Dose Liraglutide in Combination With Metformin Versus High Dose Liraglutide Alone in Treatment of Obese PCOS: Randomized Trial. BMC Endocr Disord (2017) 17(1):5. doi: 10.1186/s12902-017-0155-9

159. Papaetis GS, Filippou PK, Constantinidou KG, Stylianou CS. Liraglutide: New Perspectives for the Treatment of Polycystic Ovary Syndrome. Clin Drug Investig (2020) 40(8):695-713. doi: 10.1007/s40261-020-00942-2

160. Cena H, Chiovato L, Nappi RE. Obesity, Polycystic Ovary Syndrome, and Infertility: A New Avenue for GLP-1 Receptor Agonists. J Clin Endocrinol Metab (2020) 105(8):e2695-709. doi: 10.1210/clinem/dgaa285

161. Elkind-Hirsch K, Marrioneaux O, Bhushan M, Vernor D, Bhushan R. Comparison of Single and Combined Treatment With Exenatide and Metformin on Menstrual Cyclicity in Overweight Women With Polycystic Ovary Syndrome. J Clin Endocrinol Metab (2008) 93(7):2670-8. doi: 10.1210/jc.2008-0115

162. Chuffa LG, Lupi Júnior LA, da Maia Lima AF. Sex Steroid Receptors and Apoptosis-Related Proteins are Differentially Expressed in Polycystic Ovaries of Adult Dogs. Tissue Cell (2016) 48(1):10-7. doi: 10.1016/j.tice.2015.12.003

163. Gebremedhn S, Salilew-Wondim D, Hoelker M, Rings F, Neuhoff C, Tholen E, et al. MicroRNA-183-96-182 Cluster Regulates Bovine Granulosa Cell Proliferation and Cell Cycle Transition by Coordinately Targeting Foxol. Biol Reprod (2016) 94(6):127. doi: 10.1095/biolreprod.115.137539

164. Sun Z, Li P, Wang X, Lai S, Qiu H, Chen Z, et al. GLP-1/GLP-1r Signaling Regulates Ovarian PCOS-Associated Granulosa Cells Proliferation and Antiapoptosis by Modification of Forkhead Box Protein O1 Phosphorylation Sites. Int J Endocrinol (2020) 2020:1484321. doi: 10.1155/ 2020/1484321

165. Saad MA, Eltarzy MA, Abdel Salam RM, Ahmed MAE. Liraglutide Mends Cognitive Impairment by Averting Notch Signaling Pathway Overexpression in a Rat Model of Polycystic Ovary Syndrome. Life Sci (2021) 265:118731. doi: 10.1016/j.lfs.2020.118731

166. Abdalla MA, Deshmukh H, Atkin S, Sathyapalan T. The Potential Role of Incretin-Based Therapies for Polycystic Ovary Syndrome: A Narrative Review of the Current Evidence. Ther Adv Endocrinol Metab (2021) 12:2042018821989238. doi: 10.1177/2042018821989238

167. Gadde KM, Atkins KD. The Limits and Challenges of Antiobesity Pharmacotherapy. Expert Opin Pharmacother. (2020) 21(11):1319-28. doi: 10.1080/14656566.2020.1748599

168. Kadouh H, Chedid V, Halawi H, Burton DD, Clark MM, Khemani D, et al. GLP-1 Analog Modulates Appetite, Taste Preference, Gut Hormones, and Regional Body Fat Stores in Adults With Obesity. J Clin Endocrinol Metab (2020) 105(5):1552-63. doi: 10.1210/clinem/dgz140

169. Khoo TK, Lin J. Once-Weekly Semaglutide in Adults With Overweight or Obesity. N Engl J Med (2021) 385(1):e4. doi: 10.1056/NEJMc2106918

170. Gabery S, Salinas CG, Paulsen SJ, Ahnfelt-Rønne J, Alanentalo T, Baquero AF, et al. Semaglutide Lowers Body Weight in Rodents via Distributed Neural Pathways. JCI Insight (2020) 5(6):e133429. doi: 10.1172/ jci.insight. 133429

171. Zhang F, Tong Y, Su N, Li Y, Tang L, Huang L, et al. Weight Loss Effect of Glucagon-Like Peptide-1 Mimetics on Obese/Overweight Adults Without Diabetes: A Systematic Review and Meta-Analysis of Randomized Controlled Trials. J Diabetes (2015) 7(3):329-39. doi: 10.1111/17530407.12198

172. Rosenstock J, Sorli CH, Trautmann ME, Morales C, Wendisch U, Dailey G, et al. Once-Weekly Efpeglenatide Dose-Range Effects on Glycemic Control and Body Weight in Patients With Type 2 Diabetes on Metformin or Drug Naive, Referenced to Liraglutide. Diabetes Care (2019) 42(9):1733-41. doi: $10.2337 / \mathrm{dc} 18-2648$

173. Mirabelli M, Chiefari E, Tocci V, Caroleo P, Giuliano S, Greco E, et al. Clinical Effectiveness and Safety of Once-Weekly GLP-1 Receptor Agonist Dulaglutide as Add-On to Metformin or Metformin Plus Insulin Secretagogues in Obesity and Type 2 Diabetes. J Clin Med (2021) 10 (5):985. doi: $10.3390 / \mathrm{jcm} 10050985$ 
174. Unni S, Wittbrodt E, Ma J, Schauerhamer M, Hurd J, Ruiz-Negrón N, et al. Comparative Effectiveness of Once-Weekly Glucagon-Like Peptide-1 Receptor Agonists With Regard to 6-Month Glycaemic Control and Weight Outcomes in Patients With Type 2 Diabetes. Diabetes Obes Metab (2018) 20(2):468-73. doi: 10.1111/dom.13107

175. Halawi H, Khemani D, Eckert D, O’Neill J, Kadouh H, Grothe K, et al. Effects of Liraglutide on Weight, Satiation, and Gastric Functions in Obesity: A Randomised, Placebo-Controlled Pilot Trial. Lancet Gastroenterol Hepatol (2017) 2(12):890-9. doi: 10.1016/S2468-1253(17)30285-6

176. Seufert J, Gallwitz B. The Extra-Pancreatic Effects of GLP-1 Receptor Agonists: A Focus on the Cardiovascular, Gastrointestinal and Central Nervous Systems. Diabetes Obes Metab (2014) 16(8):673-88. doi: 10.1111/dom.12251

177. Blundell J, Finlayson G, Axelsen M, Flint A, Gibbons C, Kvist T, et al. Effects of Once-Weekly Semaglutide on Appetite, Energy Intake, Control of Eating, Food Preference and Body Weight in Subjects With Obesity. Diabetes Obes Metab (2017) 19(9):1242-51. doi: 10.1111/dom.12932

178. Friedrichsen M, Breitschaft A, Tadayon S, Wizert A, Skovgaard D. The Effect of Semaglutide $2.4 \mathrm{Mg}$ Once Weekly on Energy Intake, Appetite, Control of Eating, and Gastric Emptying in Adults With Obesity. Diabetes Obes Metab (2021) 23(3):754-62. doi: 10.1111/dom.14280

179. Larsen PJ. Mechanisms Behind GLP-1 Induced Weight Loss. Br J Diabetes Vasc Dis (2008) 8(2 Suppl):S34-41. doi: 10.1177/1474651408100525

180. Xu F, Lin B, Zheng X, Chen Z, Cao H, Xu H, et al. GLP-1 Receptor Agonist Promotes Brown Remodelling in Mouse White Adipose Tissue Through SIRT1. Diabetologia (2016) 59(5):1059-69. doi: 10.1007/s00125-016-3896-5

181. Liu H, Zhan YL, Luo GJ, Zou LL, Li Y, Lu HY. Liraglutide and Insulin Have Contrary Effects on Adipogenesis of Human Adipose-Derived Stem Cells via Wnt Pathway. Diabetes Metab Syndr Obes (2020) 13:3075-87. doi: 10.2147/ DMSO.S253097

182. Scott LJ. Liraglutide: A Review of its Use in Adult Patients With Type 2 Diabetes Mellitus. Drugs (2014) 74(18):2161-74. doi: 10.1007/s40265-014-0321-6

183. Chalasani N, Younossi Z, Lavine JE, Charlton M, Cusi K, Rinella M, et al. The Diagnosis and Management of Nonalcoholic Fatty Liver Disease: Practice Guidance From the American Association for the Study of Liver Diseases. Hepatology (2018) 67(1):328-57. doi: 10.1002/hep.29367

184. Bramante C, Tignanelli CJ, Dutta N, Jones E, Tamariz L, Clark JM, et al. Non-Alcoholic Fatty Liver Disease (NAFLD) and Risk of Hospitalization for Covid-19. medRxiv [Preprint] (2020), 2020.09.01.20185850. doi: 10.1101/ 2020.09.01.20185850

185. Vanni E, Bugianesi E, Kotronen A, De Minicis S, Yki-Järvinen H, SvegliatiBaroni G. From the Metabolic Syndrome to NAFLD or Vice Versa? Dig Liver Dis (2010) 42(5):320-30. doi: 10.1016/j.dld.2010.01.016

186. Barb D, Portillo-Sanchez P, Cusi K. Pharmacological Management of Nonalcoholic Fatty Liver Disease. Metabolism (2016) 65(8):1183-95. doi: 10.1016/j.metabol.2016.04.004

187. Gastaldelli A, Cusi K. From NASH to Diabetes and From Diabetes to NASH: Mechanisms and Treatment Options. JHEP Rep (2019) 1(4):312-28. doi: 10.1016/j.jhepr.2019.07.002

188. Sanyal AJ. Past, Present and Future Perspectives in Nonalcoholic Fatty Liver Disease. Nat Rev Gastroenterol Hepatol (2019) 16(6):377-86. doi: 10.1038/ s41575-019-0144-8

189. Lassailly G, Caiazzo R, Buob D, Pigeyre M, Verkindt H, Labreuche J, et al. Bariatric Surgery Reduces Features of Nonalcoholic Steatohepatitis in Morbidly Obese Patients. Gastroenterology (2015) 149(2):379-88. doi: 10.1053/j.gastro.2015.04.014 quiz e15-6.

190. Violi F, Cangemi R. Pioglitazone, Vitamin E, or Placebo for Nonalcoholic Steatohepatitis. N Engl J Med (2010) 363(12):1185-6. doi: 10.1056/ NEJMc1006581 author reply 1186 .

191. Somm E, Montandon SA, Loizides-Mangold U, Gaïa N, Lazarevic V, De Vito C, et al. The GLP-1R Agonist Liraglutide Limits Hepatic Lipotoxicity and Inflammatory Response in Mice Fed a Methionine-Choline Deficient Diet. Transl Res (2021) 227:75-88. doi: 10.1016/j.trsl.2020.07.008

192. Armstrong MJ, Gaunt P, Aithal GP, Barton D, Hull D, Parker R, et al. Liraglutide Safety and Efficacy in Patients With Non-Alcoholic Steatohepatitis (LEAN): A Multicentre, Double-Blind, Randomised, Placebo-Controlled Phase 2 Study. Lancet (2016) 387(10019):679-90. doi: $10.1016 / S 0140-6736(15) 00803-\mathrm{X}$
193. Newsome PN, Buchholtz K, Cusi K, Linder M, Okanoue T, Ratziu V, et al. NN9931-4296 Investigators. A Placebo-Controlled Trial of Subcutaneous Semaglutide in Nonalcoholic Steatohepatitis. N Engl J Med (2021) 384 (12):1113-24. doi: 10.1056/NEJMoa2028395

194. Fang X, Du Z, Duan C, Zhan S, Wang T, Zhu M, et al. Beinaglutide Shows Significantly Beneficial Effects in Diabetes/Obesity-Induced Nonalcoholic Steatohepatitis in Ob/Ob Mouse Model. Life Sci (2021) 270:118966. doi: 10.1016/j.lfs.2020.118966

195. Petit JM, Vergès B. GLP-1 Receptor Agonists in NAFLD. Diabetes Metab (2017) 43:2S28-33. doi: 10.1016/S1262-3636(17)30070-8

196. Dong Z, Zhuang Q, Ye X, Ning M, Wu S, Lu L, et al. Adiponectin Inhibits NLRP3 Inflammasome Activation in Nonalcoholic Steatohepatitis via AMPK-JNK/ErK1/2-Nfkb/ROS Signaling Pathways. Front Med (Lausanne) (2020) 7:546445. doi: 10.3389/fmed.2020.546445

197. Hartman ML, Sanyal AJ, Loomba R, Wilson JM, Nikooienejad A, Bray R, et al. Effects of Novel Dual GIP and GLP-1 Receptor Agonist Tirzepatide on Biomarkers of Nonalcoholic Steatohepatitis in Patients With Type 2 Diabetes. Diabetes Care (2020) 43(6):1352-5. doi: 10.2337/dc19-1892

198. He Q, Sha S, Sun L, Zhang J, Dong M. GLP-1 Analogue Improves Hepatic Lipid Accumulation by Inducing Autophagy via AMPK/mTOR Pathway. Biochem Biophys Res Commun (2016) 476(4):196-203. doi: 10.1016/ j.bbrc.2016.05.086

199. Ding S, Jiang J, Zhang G, Bu Y, Zhang G, Zhao X. Resveratrol and Caloric Restriction Prevent Hepatic Steatosis by Regulating SIRT1-Autophagy Pathway and Alleviating Endoplasmic Reticulum Stress in High-Fat Diet-Fed Rats. PloS One (2017) 12(8):e0183541. doi: 10.1371/journal.pone.0183541

200. Zheng X, Xu F, Liang H, Cao H, Cai M, Xu W, et al. SIRT1/HSF1/HSP Pathway is Essential for Exenatide-Alleviated, Lipid-Induced Hepatic Endoplasmic Reticulum Stress. Hepatology (2017) 66(3):809-24. doi: 10.1002/hep.29238

201. Fang Y, Ji L, Zhu C, Xiao Y, Zhang J, Lu J, et al. Liraglutide Alleviates Hepatic Steatosis by Activating the TFEB-Regulated Autophagy-Lysosomal Pathway. Front Cell Dev Biol (2020) 8:602574. doi: 10.3389/fcell.2020.602574

202. Tsilidis KK, Kasimis JC, Lopez DS, Ntzani EE, Ioannidis JP. Type 2 Diabetes and Cancer: Umbrella Review of Meta-Analyses of Observational Studies. BMJ (2015) 350:g7607. doi: 10.1136/bmj.g7607

203. Harding JL, Shaw JE, Peeters A, Cartensen B, Magliano DJ. Cancer Risk Among People With Type 1 and Type 2 Diabetes: Disentangling True Associations, Detection Bias, and Reverse Causation. Diabetes Care (2015) 38(2):264-70. doi: 10.2337/dc14-1996 Erratum in: Diabetes Care. 2015 Apr;38(4):734-5.

204. Shlomai G, Neel B, LeRoith D, Gallagher EJ. Type 2 Diabetes Mellitus and Cancer: The Role of Pharmacotherapy. J Clin Oncol (2016) 34(35):4261-9. doi: 10.1200/JCO.2016.67.4044

205. Yu H, Rohan T. Role of the Insulin-Like Growth Factor Family in Cancer Development and Progression. J Natl Cancer Inst (2000) 92(18):1472-89. doi: 10.1093/jnci/92.18.1472

206. Brunton SA, Wysham CH. GLP-1 Receptor Agonists in the Treatment of Type 2 Diabetes: Role and Clinical Experience to Date. Postgrad Med (2020) 132(sup2):3-14. doi: 10.1080/00325481.2020.1798099

207. Piccoli GF, Mesquita LA, Stein C, Aziz M, Zoldan M, Degobi NAH, et al. Do GLP-1 Receptor Agonists Increase the Risk of Breast Cancer? A Systematic Review and Meta-Analysis. J Clin Endocrinol Metab (2021) 106(3):912-21. doi: $10.1210 /$ clinem/dgaa891

208. Gier B, Butler PC, Lai CK, Kirakossian D, DeNicola MM, Yeh MW. Glucagon Like Peptide-1 Receptor Expression in the Human Thyroid Gland. J Clin Endocrinol Metab (2012) 97(1):121-31. doi: 10.1210/jc.20112407

209. Alves C, Batel-Marques F, Macedo AF. A Meta-Analysis of Serious Adverse Events Reported With Exenatide and Liraglutide: Acute Pancreatitis and Cancer. Diabetes Res Clin Pract (2012) 98(2):271-84. doi: 10.1016/ j.diabres.2012.09.008

210. Wenjing H, Shao Y, Yu Y, Huang W, Feng G, Li J. Exendin-4 Enhances the Sensitivity of Prostate Cancer to Enzalutamide by Targeting Akt Activation. Prostate (2020) 80(5):367-75. doi: 10.1002/pros.23951

211. Iwaya C, Nomiyama T, Komatsu S, Kawanami T, Tsutsumi Y, Hamaguchi Y, et al. Exendin-4, a Glucagonlike Peptide-1 Receptor Agonist, Attenuates 
Breast Cancer Growth by Inhibiting NF-kb Activation. Endocrinology (2017) 158(12):4218-32. doi: 10.1210/en.2017-00461

212. Nomiyama T, Kawanami T, Irie S, Hamaguchi Y, Terawaki Y, Murase K, et al. Exendin-4, a GLP-1 Receptor Agonist, Attenuates Prostate Cancer Growth. Diabetes (2014) 63(11):3891-905. doi: 10.2337/db13-1169

213. Natarajan K, Xie Y, Baer MR, Ross DD. Role of Breast Cancer Resistance Protein (BCRP/ABCG2) in Cancer Drug Resistance. Biochem Pharmacol (2012) 83(8):1084-103. doi: 10.1016/j.bcp.2012.01.002

214. Zhao HJ, Jiang X, Hu LJ, Yang L, Deng LD, Wang YP, et al. Activation of GLP-1 Receptor Enhances the Chemosensitivity of Pancreatic Cancer Cells. J Mol Endocrinol (2020) 64(2):103-13. doi: 10.1530/JME-19-0186

215. Eftekhari S, Montazeri H, Tarighi P. Synergistic Anti-Tumor Effects of Liraglutide, a Glucagon-Like Peptide-1 Receptor Agonist, Along With Docetaxel on LNCaP Prostate Cancer Cell Line. Eur J Pharmacol (2020) 878:173102. doi: 10.1016/j.ejphar.2020.173102

216. Kanda R, Hiraike H, Wada-Hiraike O, Ichinose T, Nagasaka K, Sasajima Y, et al. Expression of the Glucagon-Like Peptide-1 Receptor and Its Role in Regulating Autophagy in Endometrial Cancer. BMC Cancer (2018) 18 (1):657. doi: 10.1186/s12885-018-4570-8

217. Zhang $\mathrm{Y}, \mathrm{Xu} F$, Liang $\mathrm{H}$, Cai M, Wen X, Li X, et al. Exenatide Inhibits the Growth of Endometrial Cancer Ishikawa Xenografts in Nude Mice. Oncol Rep (2016) 35(3):1340-8. doi: 10.3892/or.2015.4476

218. He W, Yu S, Wang L, He M, Cao X, Li Y, et al. Exendin-4 Inhibits Growth and Augments Apoptosis of Ovarian Cancer Cells. Mol Cell Endocrinol (2016) 436:240-9. doi: 10.1016/j.mce.2016.07.032

219. Nie ZJ, Zhang YG, Chang YH, Li QY, Zhang YL. Exendin-4 Inhibits Glioma Cell Migration, Invasion and Epithelial-to-Mesenchymal Transition Through GLP-1R/Sirt3 Pathway. BioMed Pharmacother. (2018) 106:13649. doi: 10.1016/j.biopha.2018.07.092

220. Singh S, Chang HY, Richards TM, Weiner JP, Clark JM, Segal JB. Glucagonlike Peptide 1-Based Therapies and Risk of Hospitalization for Acute Pancreatitis in Type 2 Diabetes Mellitus: A Population-Based Matched Case-Control Study. JAMA Intern Med (2013) 173(7):534-9. doi: 10.1001/jamainternmed.2013.2720

221. Knapen LM, van Dalem J, Keulemans YC, van Erp NP, Bazelier MT, De Bruin ML, et al. Use of Incretin Agents and Risk of Pancreatic Cancer: A Population-Based Cohort Study. Diabetes Obes Metab (2016) 18(3):258-65. doi: $10.1111 /$ dom. 12605

222. Kristensen SL, Rørth R, Jhund PS, Docherty KF, Sattar N, Preiss D, et al. Cardiovascular, Mortality, and Kidney Outcomes With GLP-1 Receptor Agonists in Patients With Type 2 Diabetes: A Systematic Review and MetaAnalysis of Cardiovascular Outcome Trials. Lancet Diabetes Endocrinol (2019) 7(10):776-85. doi: 10.1016/S2213-8587(19)30249-9 Erratum in: Lancet Diabetes Endocrinol. 2020 Mar;8(3):e2.

223. Gumbs AA. Obesity, Pancreatitis, and Pancreatic Cancer. Obes Surg (2008) 18(9):1183-7. doi: 10.1007/s11695-008-9599-3

224. Zhao H, Wang L, Wei R, Xiu D, Tao M, Ke J, et al. Activation of GlucagonLike Peptide-1 Receptor Inhibits Tumourigenicity and Metastasis of Human Pancreatic Cancer Cells via PI3K/Akt Pathway. Diabetes Obes Metab (2014) 16(9):850-60. doi: 10.1111/dom.12291
225. Zhao H, Wei R, Wang L, Tian Q, Tao M, Ke J, et al. Activation of GlucagonLike Peptide-1 Receptor Inhibits Growth and Promotes Apoptosis of Human Pancreatic Cancer Cells in a cAMP-Dependent Manner. Am J Physiol Endocrinol Metab (2014) 306(12):E1431-41. doi: 10.1152/ajpendo.00017.2014

226. Suh S, Kim KW. Diabetes and Cancer: Cancer Should Be Screened in Routine Diabetes Assessment. Diabetes Metab J (2019) 43(6):733-43. doi: 10.4093/ dmj.2019.0177

227. Kosowska A, Gallego-Colon E, Garczorz W, Kłych-Ratuszny A, Aghdam MRF, Woz Niak M, et al. Exenatide Modulates Tumor-Endothelial Cell Interactions in Human Ovarian Cancer Cells. Endocr Connect (2017) 6 (8):856-65. doi: 10.1530/EC-17-0294

228. Zhang D, Ma M, Liu Y. Protective Effects of Incretin Against Age-Related Diseases. Curr Drug Delivery (2019) 16(9):793-806. doi: 10.2174/ 1567201816666191010145029

229. Drab SR. Glucagon-Like Peptide-1 Receptor Agonists for Type 2 Diabetes: A Clinical Update of Safety and Efficacy. Curr Diabetes Rev (2016) 12(4):40313. doi: $10.2174 / 1573399812666151223093841$

230. Borner T, Shaulson ED, Tinsley IC, Stein LM, Horn CC, Hayes MR, et al. A Second-Generation Glucagon-Like Peptide-1 Receptor Agonist Mitigates Vomiting and Anorexia While Retaining Glucoregulatory Potency in Lean Diabetic and Emetic Mammalian Models. Diabetes Obes Metab (2020) 22 (10):1729-41. doi: 10.1111/dom.14089

231. Samson SL, Garber A. GLP-1R Agonist Therapy for Diabetes: Benefits and Potential Risks. Curr Opin Endocrinol Diabetes Obes (2013) 20(2):87-97. doi: 10.1097/MED.0b013e32835edb32

232. Kawai T, Sun B, Yoshino H, Feng D, Suzuki Y, Fukazawa M, et al. Structural Basis for GLP-1 Receptor Activation by LY3502970, an Orally Active Nonpeptide Agonist. Proc Natl Acad Sci U S A (2020) 117(47):29959-67. doi: 10.1073/pnas.2014879117

233. Choe HJ, Cho YM. Peptidyl and Non-Peptidyl Oral Glucagon-Like Peptide1 Receptor Agonists. Endocrinol Metab (Seoul) (2021) 36(1):22-9. doi: 10.3803/EnM.2021.102

Conflict of Interest: The authors declare that the research was conducted in the absence of any commercial or financial relationships that could be construed as a potential conflict of interest.

Publisher's Note: All claims expressed in this article are solely those of the authors and do not necessarily represent those of their affiliated organizations, or those of the publisher, the editors and the reviewers. Any product that may be evaluated in this article, or claim that may be made by its manufacturer, is not guaranteed or endorsed by the publisher.

Copyright () 2021 Zhao, Wang, Wen, Lu, Cui, Fu, Xue, Liu and Zhang. This is an open-access article distributed under the terms of the Creative Commons Attribution License (CC BY). The use, distribution or reproduction in other forums is permitted, provided the original author(s) and the copyright owner(s) are credited and that the original publication in this journal is cited, in accordance with accepted academic practice. No use, distribution or reproduction is permitted which does not comply with these terms. 